University of Wollongong

Research Online

Australian Institute for Innovative Materials -

Papers

Australian Institute for Innovative Materials

$1-1-2017$

Synthesis and characterisation of MWNT/chitosan and MWNT/chitosancrosslinked buckypaper membranes for desalination

Ahmed Alshahrani

King Abdulaziz City For Science And Technology

Habis Al-Zoubi

Al-Hussein Bin Talal University

Long D. Nghiem

University of Wollongong, longn@uow.edu.au

Marc in het Panhuis

University of Wollongong, panhuis@uow.edu.au

Follow this and additional works at: https://ro.uow.edu.au/aiimpapers

Part of the Engineering Commons, and the Physical Sciences and Mathematics Commons

Research Online is the open access institutional repository for the University of Wollongong. For further information contact the UOW Library: research-pubs@uow.edu.au 


\title{
Synthesis and characterisation of MWNT/chitosan and MWNT/chitosan- crosslinked buckypaper membranes for desalination
}

\author{
Abstract \\ Novel buckypaper (BP) membranes for nanofiltration application were fabricated from multi-walled \\ carbon nanotubes (MWNT) and biopolymer containing quaternary amine groups (chitosan and chitosan- \\ crosslinked by in-situ amine crosslinking). Characteristics of the BP membranes were systematically \\ characterized in terms of mechanical (tensile strengths varied between $49 \pm 4$ and $59 \pm 3 \mathrm{MPa}$ ) and \\ electrical properties $(60 \pm 1$ to $70 \pm 1 \mathrm{~S} / \mathrm{cm})$, contact angle $\left(76 \pm 3^{\circ}\right.$ to $\left.102 \pm 3^{\circ}\right)$, surface morphology, \\ membrane swelling, pore size, surface charge, solubility, water permeability (ranging from $019 \pm 0.01$ to \\ $0.87 \pm 0.03 \mathrm{~L} \mathrm{~m}-2 \mathrm{~h}-1$ bar- 1 ), and salts rejection (80-95\% for $\mathrm{MgCl} 2,21-63 \%$ for $\mathrm{NaCl}, 18-37 \%$ for $\mathrm{MgSO} 4$ \\ and $6-14 \%$ for $\mathrm{Na} 2 \mathrm{SO} 4)$. These BP membranes were able to sustain up to 18 bar of pressure. Their \\ properties were significantly affected by the type of biopolymer modifiers. The highest water permeability \\ was obtained with the MWNT/chitosan BP membrane, while the MWNT/chitosan-crosslinked membranes \\ showed the best salt rejection performance. In addition, separation performance by these membranes \\ appeared to be governed by the unhydrated radii of these inorganic salts.

\section{Disciplines} \\ Engineering | Physical Sciences and Mathematics

\section{Publication Details} \\ Alshahrani, A. A., Al-Zoubi, H., Nghiem, L. D. \& in het Panhuis, M. (2017). Synthesis and characterisation of \\ MWNT/chitosan and MWNT/chitosan-crosslinked buckypaper membranes for desalination. Desalination, \\ 418 60-70.
}


1 Synthesis and Characterization of MWNT/Chitosan and MWNT/

2 Chitosan-Crosslinked Buckypaper Membranes for Desalination

3 Ahmed A. Alshahrani ${ }^{1 *}$, Habis Al-Zoubi ${ }^{2}$, Long D. Nghiem ${ }^{3}$ and Marc in het Panhuis ${ }^{4}$

$4 \quad{ }^{1}$ National Centre for Technology Radiological Applications, King Abdul Aziz City for Science and

5 Technology, Riyadh 11442, Saudi Arabia.

$6 \quad{ }^{2}$ Department of Chemical Engineering, College of Engineering, Al-Hussein Bin Talal University, Jordan

$7 \quad{ }^{3}$ School of Civil Mining and Environmental Engineering, Wollongong, NSW 2527, Australia.

$8{ }^{4}$ Intelligent Polymer Research Institute, ARC Centre of Excellence for Electromaterials Science, AIIM

9 Facility, University of Wollongong, Wollongong, NSW 2527, Australia.

\section{Abstract:}

12 Novel buckypaper (BP) membranes for nanofiltration application were fabricated from 13 multi-walled carbon nanotubes (MWNT) and biopolymer containing quaternary amine 14 groups (chitosan and chitosan-crosslinked by in-situ amine crosslinking). Characteristics 15 of the BP membranes were systematically characterized in terms of mechanical (tensile 16 strengths varied between $49 \pm 4$ and $59 \pm 3 \mathrm{MPa})$ and electrical properties $(60 \pm 1$ to $70 \pm$ $171 \mathrm{~S} / \mathrm{cm})$, contact angle $\left(76 \pm 3^{\circ}\right.$ to $\left.102 \pm 3^{\circ}\right)$, surface morphology, membrane swelling, 18 pore size, surface charge, solubility, water permeability (ranging from $019 \pm 0.01$ to 0.87 $19 \pm 0.03 \mathrm{~L} \mathrm{~m}^{-2} \mathrm{~h}^{-1} \mathrm{bar}^{-1}$ ), and salt rejection (80 - 95\% for $\mathrm{MgCl}_{2}, 21-63 \%$ for $\mathrm{NaCl}, 18-37$

$20 \%$ for $\mathrm{MgSO}_{4}$ and $6-14 \%$ for $\mathrm{Na}_{2} \mathrm{SO}_{4}$ ). These BP membranes were able to sustain up to 2118 bar of pressure. Their properties were significantly affected by the type of biopolymer 22 modifiers. The highest water permeability was obtained with the MWNT/chitosan BP 23 membrane, while the MWNT/chitosan-crosslinked membranes showed the best salt 24 rejection performance. In addition, these BP membranes achieved considerable salt 25 rejection. In addition, separation performance by these membranes appeared to be 26 governed by the unhydrated radii of these inorganic salts.

27 Keywords: Carbon nanotube, nanofiltration membrane, buckypapers, chitosan, 28 desalination. 


\section{$31 \quad 1 . \quad$ Introduction}

Carbon nanotubes (CNTs) have attracted significant scientific attention in recent years. They are promising materials for the fabrication of functional membrane materials due to their excellent electrical, mechanical, thermal properties and high surface area [15]. For example, molecular dynamic simulations of CNTs membranes have demonstrated unexpectedly much higher water permeability comparing to other known porous materials $[6,7]$. As a result, CNTs matrices have been evaluated for membrane applications. Hinds et al. [8] constructed an array of aligned carbon nanotubes (CNTs) incorporated across a polymer film to form a well-ordered nanoporous membrane structure. They observed a permeation fate of four to five times higher compared to conventional fluid flow calculated by the Hagen-Poiseuille equation. In another study, aligned CNTs in silicon nitride composite membranes were fabricated using chemical vapor deposition by Holt et al. [9]. The CNTs in silicon composite membrane achieved faster gas and water permeation than would be expected. However, preparing aligned CNTs is still limited to small-scale, costly and difficult to reproduce techniques $[4,10]$.

As an alternative to the aligned structure, CNTs can be dispersed in an aqueous solution using sonicator and dispersant and reform to obtain composite thin membrane with fast transport rate and easy to scale-up operation. Recent research has significantly improved the mass transport rate of non-aligned CNTs membranes. For instance, single walled carbon nanotubes (SWNT) with poly(imid siloxane) nano-composite membranes were prepared by Kim et al. [11] and they reported that the mass transport rate of $\mathrm{O}_{2}, \mathrm{~N}_{2}$ and $\mathrm{CH}_{4}$ increased by increasing SWNTs content in the nano-composite membranes. Polyvinyl alcohol (PVA) was coated with a nonporous hydrophilic polymer and oxidized multi-walled carbon nanotubes (MWNT) nano-composite membranes were fabricated by Wang et al. [12]. Their results showed considerable improvement in the water flux and solute rejection.

Recent investigations have shown that buckypaper (BP) fabricated from aligned arrays of CNTs can have a free volume of up to $70 \%$ of the total porous network structure. Potential applications of BP membranes have been explored in several fields including artificial muscles, hydrogen storage, sensors, actuators, for structural 
61 reinforcement in polymer composites and in the membrane separation process $[13,14]$.

62 CNTs BP membranes have high permeability towards water and gases as well as good 63 selectivity between small and large molecules $[15,16]$. The internal structure of BPs 64 contains small and large pores due to the spaces between bundles of CNTs, while the 65 pore size distributions of BPs are controlled by the pores with diameters of $100 \mathrm{~nm}$ or 66 above[17]. The sizes of the BP pores are wholly dependent on the arrangements and sizes 67 of the CNTs. BPs can also absorb gas and liquid to $60-70 \%$ of their volume because of 68 intrabundle pores and interbundle gaps. This porosity, coupled with high strength, rigidity and exceptional flow rates, suggests that BPs could make outstanding membranes [18].

CNTs have the tendency to aggregate. Thus, a dispersant is required to solubilize 71 for the fabrication of BP membranes. Several studies have used chitosan as a dispersant 72 for preparing a CNTs BP membranes due to their ability to interact with CNTs to form an 73 aqueous solution [19, 20]. Chitosan is a polymer of randomly distributed a-(1-4)-linked 74 D-glucosamine and N-acetyl-D-glucosamine. Chitosan is commercially made by 75 deacetylation of chitin from the exoskeleton of crustaceans. The degree of deacetylation 76 (DDA) controls the solubility of chitosan in acidic solution, the ability to modification 77 supramolecular structures through hydrogen bonding [21]. Chitosan addition allows for 78 BP membrane preparation using solvent evaporation with a low concentration of organic 79 acid such as acetic acid $[22,23]$. Several studies have also reported that chitosan can be modified via chemical modifications to create functional derivatives of chitosan [22-25].

81 These modifications could enhance the mechanical strength, chemical stability, 82 biocompatibility and hydrophilicity of chitosan. For example, the cross-linking of 83 chitosan by dialdehydes [26] or epoxides [27, 28] may lead to a denser network 84 structure, enhancing the mechanical properties and improving the resistance of the 85 membrane against acid, alkali and chemical.

86 This study reports the fabrication and characterisation of three BP membranes 87 prepared from MWNTs and biopolymer dispersants namely chitosan, chitosan-glycerin 88 (CHIT- glycerin) and chitosan-polyethylene glycol diglycidyl ether (CHIT-PEGDE). 89 Water flux and rejection characteristics of these BP membranes were investigated under 
different experimental conditions. Key parameters that control the optimization of these

91 BP membranes were also systematically examined.

92

93

\section{EXPERIMENTAL}

\subsection{Materials}

Unfunctionalised thin MWNTs (Nanocyl $^{\mathrm{TM}}$ 3100) were obtained from Nanocyl, Belgium. All MWNT samples had $95 \%$ purity and were used without any further purification. Low molecular weight chitosan with a deacetylation degree of $82 \%$ and a viscosity of $200-800$ cP (1\% in 1\% acetic acid) was obtained from Sigma-Aldrich. Glacial acetic acid with $99.7 \%$ purity was purchased from Asia Pacific Specialty (APS) Chemicals Limited, Australia. Glycerin was obtained from Sigma-Aldrich, United States. Polyethylene glycol-diglycidyl ether (PEGDE) (Mn 526) was obtained from SigmaAldrich and they were used for crosslinking chitosan. On the other hand, $\mathrm{NaCl}, \mathrm{MgCl}_{2}$, and $\mathrm{Na}_{2} \mathrm{SO}_{4}$ were purchased from Sigma-Aldrich. Anhydrous $\mathrm{MgSO}_{4}$ was purchased from Scharlau, Spain. HCl, methanol and ethanol were bought from Ajax Finechem Pty Ltd., Australia. The filter for MWNT dispersions comprised of rectangular pieces of polyvinylidene fluoride (PVDF) from Millipore (Ireland) in the form of a hydrophobic commercial membrane with a nominal pore size of $0.22 \mu \mathrm{m}$. Another hydrophobic PTFE membrane filter with pore sizes $5.0 \mu \mathrm{m}$ was also purchased from Millipore (Ireland) and used to remove any particulates from the chitosan solution. All the solutions and dilutions in this study were prepared using Milli- $\mathrm{Q}^{\circledR}$ water (resistivity of $18.2 \mathrm{M} \Omega \mathrm{cm}$ ).

\subsection{BP membrane preparation}

\subsubsection{Preparation of chitosan crosslinking BP membranes}

The chitosan solutions were prepared by dissolving $6 \mathrm{~g}$ of chitosan $(0.2 \% \mathrm{w} / \mathrm{v})$ in $3 \mathrm{~L}$ of an aqueous solution containing $1 \%(\mathrm{v} / \mathrm{v})$ acetic-acid. The solutions were heated for $3 \mathrm{~h}$ at $80{ }^{\circ} \mathrm{C}$ and stirred for $24 \mathrm{~h}$ until the chitosan dissolved completely. The solutions were then left overnight to cool at $21{ }^{\circ} \mathrm{C}$. The homogenous solutions were filtered through a $5.0 \mu \mathrm{m}$ hydrophobic PTFE membrane to remove any undissolved chitosan particles. The final homogenous solution after filtration was divided into three groups. 
(i) Chitosan: This was prepared with the homogenous chitosan solution $(0.2 \%$ w/v) without any additives.

(ii) Chitosan-glycerin: This was prepared with the homogenous chitosan solution $(0.2 \% \mathrm{w} / \mathrm{v})$ and $0.8 \mathrm{~g}$ of glycerin (20\% chitosan mass).

(iii) Chitosan-PEGDE: This was prepared with chitosan $(0.2 \% \mathrm{w} / \mathrm{v})$ and $0.8 \mathrm{~g}$ of 123 PEGDE (20\% chitosan mass). Each of these two solutions was heated for $2 \mathrm{~h}$ at 50-70 $124{ }^{\circ} \mathrm{C}$, stirred $24 \mathrm{~h}$ and left overnight to cool at $21{ }^{\circ} \mathrm{C}$. chitosan-PEGDE solutions and mixed by sonication for $30 \mathrm{~min}$. The above procedure was repeated 10 times to produce $150 \mathrm{~mL}$ of the MWNT dispersion solution. Each dispersion solution was diluted up to $250 \mathrm{~mL}$ and then filtrated through hydrophobic PVDF filter paper $(142 \mathrm{~mm}$, pore size $0.22 \mu \mathrm{m})$ using a vacuum pump at 30-40 mbar. The top of the filtration system (custom-built transport cell unit) was covered with 131 aluminum foil to avoid evaporative loss. The large BP membrane produced on the 132 filtration sheet was placed to dry between absorbent paper sheets with small, flat glasses 133 at the top and left for $24 \mathrm{~h}$ at $21^{\circ} \mathrm{C}$. The dry BP membrane was then peeled from the 134 filtration sheet.

\subsection{Characterisation techniques and instrumentation}

The following instrumentation methods were adopted to analyse and characterise different properties of the BP membranes.

\subsubsection{UV-vis-NIR spectroscopy}

The absorption of all dispersion solutions (MWNT/chitosan, MWNT/chitosanglycerin and MWNT/chitosan-PEGDE) was examined from 300-1000 nm using a Cary ${ }^{\circledR}$ 500 UV-vis-NIR spectrophotometer. All above dispersion solutions $(0.1 \mathrm{~mL})$ were diluted in a small vial $(20 \mathrm{~mL})$ by Milli-Q water $(15 \mathrm{~mL})$. The dispersion solutions were taken into a quartz cuvette (1-cm path length) and spectra were measured at estimated 21 ${ }^{\circ} \mathrm{C}$. 


\subsubsection{Electrical conductivity}

146

147

148

The electrical resistance of three BP membranes was measured at room temperature $\left(21{ }^{\circ} \mathrm{C}\right.$ and $\left.45 \% \mathrm{RH}\right)$ through using the two-point probe method [29]. All BP samples were prepared via cutting them into small thin strips of $4 \mathrm{~mm} \times 30 \mathrm{~mm}$. Thicknesses of all samples were also determined with a Mitutoyo Digital Micrometer, and width was estimated by optical microscope. The membrane strips were then placed on glass slides using double-sided tape. Both Silver paint (SPI-paint 05002-AB) and copper tape (3M \#1181 electrical tape) were used to ensure low contact resistance. The sample-electrode contacts were located under standard compression $\left(10^{5} \mathrm{~Pa}\right)$ by using bull clips. Another glass slide was clasped over the membrane using bull clips to be sure continuous connection during the analysis.

An arbitrary waveform generator (Agilent 33220A) was utilize to apply a stepwise DC-voltage ramp from -0.1 to $+0.1 \mathrm{~V}$. The current (I) and voltage (V) responses were estimated using a digital multimeter (Agilent 34410A). Measurements were restated for at least five channel lengths from $0.5-3 \mathrm{~cm}$. Electrical resistance as a function of changed length was measured using Ohm's law. This was repeated minimum of five different lengths for each sample to determine the resistance.

\subsubsection{Contact-angle measurement}

The hydrophobicity of membrane is commonly determined by measuring the contact angle of a water droplet on its surface. The contact angles of all buckypaper membranes were examined using the sessile drop method and a DataPhysics ${ }^{\circledR}$ SCA20 Goniometer fitted with a digital camera. All samples $(4 \mathrm{~mm} \times 35 \mathrm{~mm})$ were clamped flat on a glass microscope slide and $2-\mu \mathrm{L}$ water (Milli-Q, Millipore) droplets were located on the surface of the membranes.

\subsubsection{Membrane swelling}

BP membranes were cut into thin strips $(4 \mathrm{~mm} \times 10 \mathrm{~mm})$ and their thicknesses were determined with a Mitutoyo Digital Micrometer. The weight of each sample was measured using a digital balance (Mettler XS 64). The samples were immersed and kept 
173 for $24 \mathrm{~h}$ at $21^{\circ} \mathrm{C}$ in different solutions (water/acetic acid at 1, 3 and $5 \% \mathrm{w} / \mathrm{v}$ ) and $3 \mathrm{M}$ of

174 sodium hydroxide solution. The strips were taken out at regular intervals, blotted to

175 remove excess liquid and weighed. The degree of swelling (SW\%) is calculated using:

176

$$
S W \%=\frac{W_{S}-W_{o}}{W_{o}} \times 100 \%
$$

177 where $w_{s}$ is the weight of swollen $\mathrm{BP}$ membrane and $w_{o}$ is the weight of the dry 178 membrane.

179

\subsubsection{Scanning electron microscope}

BP membrane morphology was obtained using a JEOL JSM-7500FA SEM at the Electron Microscopy Centre of the University of Wollongong. BP membrane samples were dried in an oven (Binder) at $50{ }^{\circ} \mathrm{C}$ for $24 \mathrm{~h}$, and the non-conductive material was coated with gold to improve imaging. They were then mounted onto a brass stub using conductive carbon tape. A 5-kV electric field was used for the measurement. To examine the cross-sectional images, the samples were frozen in liquid nitrogen and carefully snapped open to expose the interior.

\subsubsection{Mechanical testing}

Tensile testing was carried out using a Shimadzu EZ-S tensile tester. Five strips (approximately $4 \mathrm{~mm} \times 10 \mathrm{~mm}$ ) of a BP membrane sample were used and their thickness was measured using a Mitutoyo IP65 Digital Micrometer. The membrane samples were then located between two parallel plates at $21^{\circ} \mathrm{C}$ and $45 \% \mathrm{RH}$.

\subsubsection{Surface area and pore-size distributions of membranes}

The surface areas and pore-size distributions of the BP membranes were estimated using a Micrometric ASAP-2020 analyser at King Abdulaziz City for Science and Technology (KACST), Saudi Arabia. The BP samples were cut into small pieces $(2 \times$ $2 \mathrm{~mm}$ ) and then de-gassed at $80{ }^{\circ} \mathrm{C}$ for $16 \mathrm{~h}$ under vacuum before being tested. The surface areas and pore volumes were determined for all BP membranes by nitrogen adsorption/desorption technique at $77 \mathrm{~K}$. Nitrogen adsorption/desorption isotherms were performed using the Brunauer, Emmett, Teller (BET) method to determine the sample 
200 surface areas [30]. The $\mathrm{N}_{2}$ isotherms were employed to calculate both small and large 201 pore sizes of the sample using the Barret, Joyner and Halenda (BJH) [31] and Horvath202 Kawazoe (HK) [32] methods.

\subsubsection{Zeta Potential}

Surface charge of the BP membranes was examined using a SurPASS 206 measurements were conducted using $1 \mathrm{mM} \mathrm{KCl}$ of background electrolyte solution. $\mathrm{HCl}$ 207 and $\mathrm{KOH}$ solutions were used to adjust the $\mathrm{pH}$ by automatic titration.

\section{$208 \quad$ 2.3.9 Permeability and salt-rejection behaviors}

209

210

218 feed solution was maintained at $20 \pm 2{ }^{\circ} \mathrm{C}$ throughout the experiment with the help of a 219 chiller (Series Water Chiller 001-D081 ISS E, Aquacooler, Australia). 


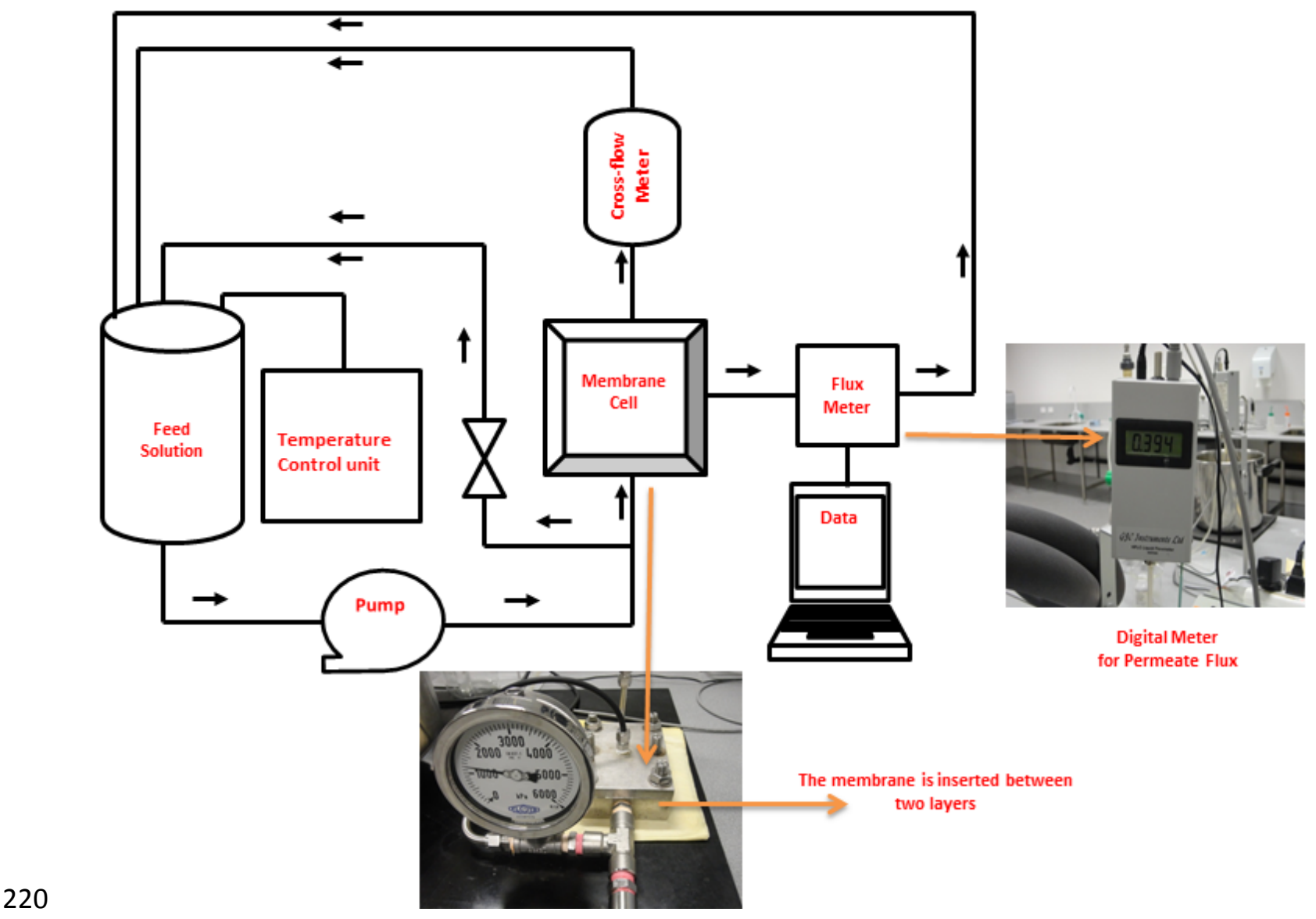

221 Fig. 1. Schematic diagram of a crossflow unit (RO/NF system).

The effective membrane area was approximately $40 \mathrm{~cm}^{2}$. A standardized 224 conductivity and $\mathrm{pH}$ meter (Thermo Scientific $^{\mathrm{TM}}$ conductivity meter Orion 4-Star ${ }^{\mathrm{TM}}$, 225 Singapore) was used to estimate various salt concentrations ( $\mathrm{NaCl}, \mathrm{MgSO}_{4}, \mathrm{MgCl}_{2}$ and $\left.226 \mathrm{Na}_{2} \mathrm{SO}_{4}\right)$ in the feed and permeate water. The percentage observed rejection $\left(\mathrm{R}_{\mathrm{o}} \%\right)$ of the 227 salts is determined from the permeate and feed samples using the following equation 228 [33]:

$$
R_{o} \%=\left(1-\frac{C_{p}}{C_{f}}\right) 100 \%
$$

230 where $\mathrm{C}_{\mathrm{p}}$ and $\mathrm{C}_{f}$ are salt concentrations on the permeate and the feed streams 231 respectively. 
Initially, this experiment was carried out at a crossflow velocity of $34.6 \mathrm{~cm} / \mathrm{s}$ by

233 determining the pure-water flux, followed by the addition of the salt into the feed solution

234 to prepare $2 \mathrm{~g} / \mathrm{L}$ (concentration of salt) and measurement of the permeate water flux and 235 permeate salt concentration. This step was measured at 10 and 16 bar of applied pressure.

236 To evaluate the influence of the solution $\mathrm{pH}$ salt rejection, the solution $\mathrm{pH}$ was 237 incrementally increased to $\mathrm{pH} 10$ by adding a small volume of $1 \mathrm{M} \mathrm{KOH}$ and then 238 incrementally decreasing the $\mathrm{pH}$ by dropwise addition of $1 \mathrm{M} \mathrm{HCl}$.

\section{3. RESULTS AND DISCUSSION}

\subsection{Dispersion of MWNT using Chitosan and Chitosan-crosslinked}

Three solutions (chitosan, chitosan-glycerin and chitosan-PEGDE) were 242 successfully used to prepare MWNT dispersions to fabricate BP membranes. UV-vis243 NIR spectroscopy was used to compare non-crosslinked and crosslinked chitosan for 244 dispersing MWNTs (Fig 2.A). The absorbance of MWNT/chitosan dispersion was 245 measured at wavelengths of 300-1000 $\mathrm{nm}$. This absorbance was amplified by increasing 246 the sonication time, which is consistent with previous studies in the literature $[15,16,20]$. 247 In Fig 2.B, the absorbance of the dispersions at $660 \mathrm{~nm}$ was plotted as a function of 248 sonication time. This wavelength $(660 \mathrm{~nm})$ was chosen to avoid absorbance attributable 249 to dispersant (chitosan or crosslinked chitosan) and the solvent (Milli-Q water). Results 250 in Fig 2.B suggest that $10 \mathrm{~min}$ sonication was sufficient for good dispersion of the 251 MWNT in the solution containing chitosan and/or chitosan-glycerin, whereas 20 min 252 sonication was necessary to disperse MWNT in the solution containing chitosan-PEGDE. 253 The results in Fig 2.B suggest that $20 \mathrm{~min}$ is a suitable amount of time to disperse the 254 MWNT in both solutions (chitosan and crosslinked chitosan). Accordingly, sonication 255 time of 20 min was chosen to ensure significant dispersion of the MWNTs. 

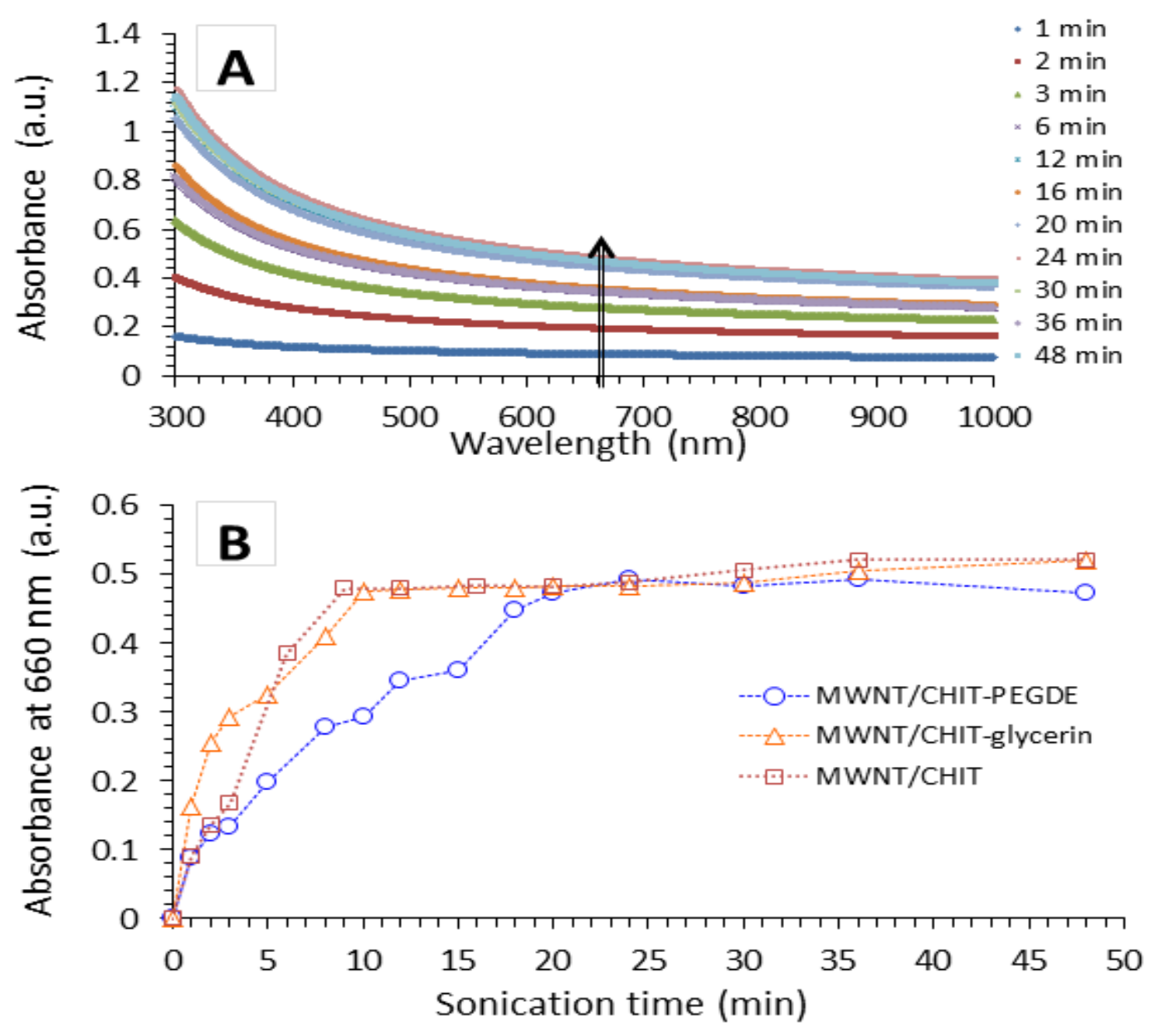

257 Fig 2. A) UV-vis spectra of MWNT/chitosan dispersion as a function of sonication time and B) comparison 258 of the effect of increasing sonication time on the absorbance at $660 \mathrm{~nm}$ of MWNT/chitosan, MWNT/chitosan-glycerin and MWNT/chitosan-PEGDE dispersions.

\section{$261 \quad 3.2 \quad$ Electrical properties of BP membranes}

The membrane conductivity can potentially be regulated by an electric potential

263 to improve separations performance [34]. Consequently, the electrical properties of the 264 BP membranes were investigated. The I-V characteristics of MWNT/chitosan, 265 MWNT/chitosan-glycerin and MWNT/ chitosan-PEGDE dispersions membranes were 266 determined using the two-point probe method under ambient conditions of $21{ }^{\circ} \mathrm{C}$ and 45 $267 \%$ relative humidity. All BP membranes showed linear I-V characteristics, indicating 268 ohmic behavior (Fig 3). 


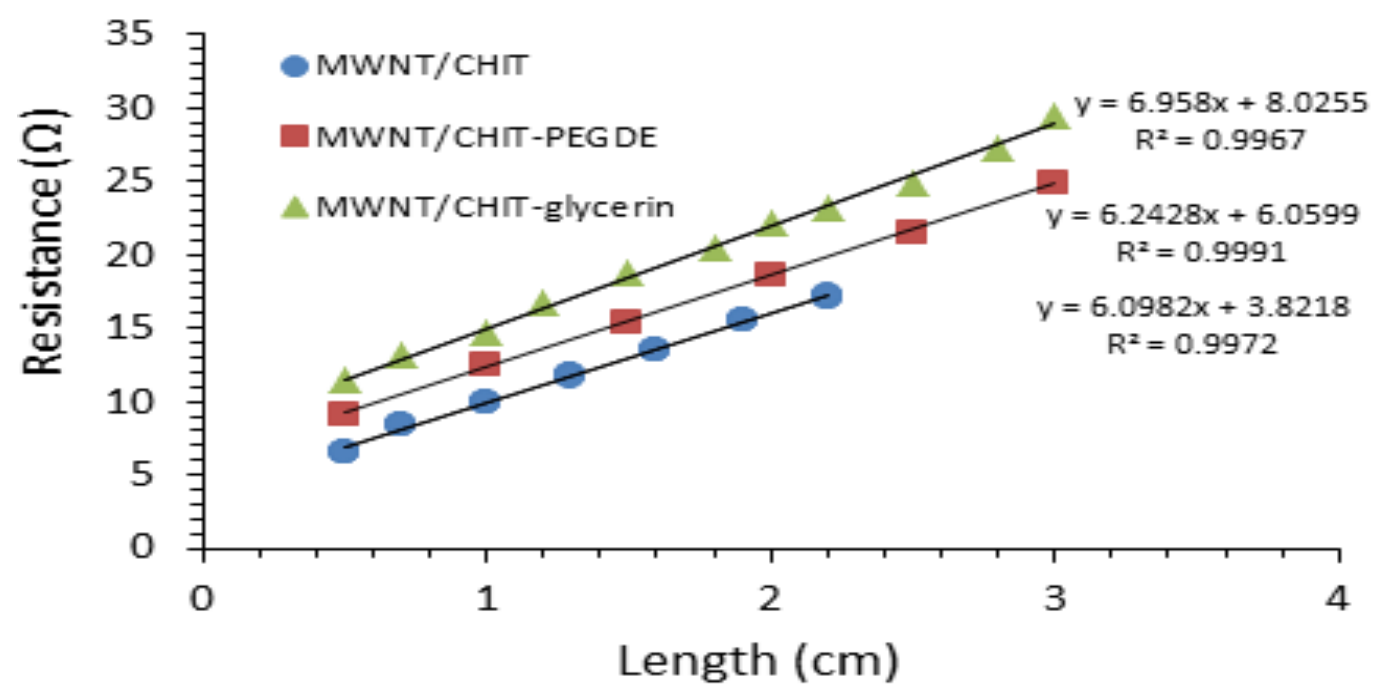

270

271

Fig 3. Resistance as a function of sample length for three different BP membranes.

272

273

274

275

276

277

278

279

280

281

282

283

284

285

286

287

288

289

The electrical conductivity of MWNT/chitosan and MWNT/chitosan-crosslinked (chitosan-glycerin and chitosan-PEGDE) was determined from the linear regression of resistance against length (Fig 3 ) using equation $3[15,20]$ :

$$
R_{T}=\frac{1}{\sigma A} l+R_{c}
$$

$\mathrm{R}_{\mathrm{T}}$ is the total resistance of BP membranes, which related to its length $(l)$ and $\sigma$ is the conductivity of the BP membranes. A is the cross section area of the sample. The conductivity value in Table $1(70 \pm 1 \mathrm{~S} / \mathrm{cm})$ of MWNT/chitosan was slightly higher than that of the MWNT/chitosan-crosslinked (MWNT/chitosan-glycerin $(66 \pm 1 \mathrm{~S} / \mathrm{cm})$ and MWNT/chitosan-PEGDE $(60 \pm 1 \mathrm{~S} / \mathrm{cm}))$ membranes. The chitosan-crosslinked as a dispersant did not significantly affect the electrical conductivity of the MWNTs. It is noted that the conductivity values of MWNT/chitosan and MWNT/chitosan-crosslinked BP membranes investigated here were higher than to those seen previously with Trix or Cipro (Table 1) [16]. For example, the conductivity values of the MWNT-Trix and MWNT-cipro BPs were $24 \pm 16$ and $42 \pm 1 \mathrm{~S} / \mathrm{cm}$ respectively (lower than those of the three investigated membranes). Therefore, results in Table 1 suggest that the conductivity of BP membranes (MWNT/chitosan and MWNT/chitosan-crosslinked) is not affected by the concentration of these biopolymers (chitosan and chitosan-crosslinked). 
Table 1. Physical properties of MWNT-chitosan and MWNT-chitosan-crosslinked BP membranes*.

\begin{tabular}{|c|c|c|c|c|c|c|c|}
\hline BP membrane & $\begin{array}{c}\text { Contact } \\
\text { angle } \\
\left(^{\circ}\right)\end{array}$ & $\begin{array}{c}\text { Conductivity } \\
\qquad \mathrm{S} / \mathrm{cm}\end{array}$ & $\begin{array}{c}\text { Thickness } \\
(\mu \mathrm{m})\end{array}$ & $\begin{array}{c}\text { Elongation } \\
(\%)\end{array}$ & $\begin{array}{l}\text { Tensile } \\
\text { strength } \\
(\mathrm{MPa})\end{array}$ & $\begin{array}{l}\text { Young's } \\
\text { modulus } \\
(\mathrm{GPa})\end{array}$ & $\begin{array}{c}\text { Toughness } \\
\mathrm{J} / \mathrm{g}\end{array}$ \\
\hline MWNT/Trix $^{a}$ & $55 \pm 10$ & $24 \pm 16$ & - & $1.3 \pm 0.2$ & $6 \pm 3$ & $0.6 \pm 0.3$ & $0.1 \pm 0.03$ \\
\hline${\mathrm{MWNT} / \text { cipro }^{a}}^{a}$ & $41 \pm 5$ & $42 \pm 1$ & - & $0.5 \pm 0.2$ & $6 \pm 2$ & $1.3 \pm 0.1$ & $0.04 \pm 0.01$ \\
\hline $\begin{array}{l}\text { MWNT/ } \tau- \\
\text { carrageenan }{ }^{b}\end{array}$ & $77 \pm 1$ & - & - & $3.4 \pm 0.6$ & $24 \pm 1$ & $2.7 \pm 0.7$ & - \\
\hline MWNT/chitosan & $102 \pm 3$ & $70 \pm 1$ & $52 \pm 3$ & $5.7 \pm 0.5$ & $56 \pm 3$ & $2.9 \pm 0.1$ & $2.1 \pm 0.3$ \\
\hline $\begin{array}{l}\text { MWNT/chitosan } \\
\text { - glycerin }\end{array}$ & $80 \pm 2$ & $66 \pm 1$ & $52 \pm 6$ & $6.4 \pm 2$ & $49 \pm 4$ & $2.8 \pm 0.2$ & $2.2 \pm 0.8$ \\
\hline $\begin{array}{l}\text { MWNT/chitosan } \\
\text { - PEGDE }\end{array}$ & $76 \pm 3$ & $60 \pm 1$ & $58 \pm 4$ & $8.1 \pm 2$ & $59 \pm 3$ & $2.7 \pm 0.2$ & $2.3 \pm 0.2$ \\
\hline
\end{tabular}

291 alues obtained are the average of at least five samples, with the errors estimated from the standard deviation of $29 \mathrm{l}$ measurements. ${ }^{a}$ Data for MWNT/Trix and MWNT/cipro taken from reference[16]. ${ }^{\mathrm{b}}$ Data for MWNT/ $\tau$ 293rrageenan taken from reference[42].

\section{$295 \quad 3.3 \quad$ Wettability of BP membranes}

296 Hydrophobicity provides information about the nature of the membrane surface, 297 and contact angle determines the hydrophobicity; that is, if the contact angle is high, the 298 material is hydrophobic. The MWNT/chitosan (un-crosslinked chitosan) BP membrane 299 has a significantly higher contact angle $\left(102 \pm 3^{\circ}\right)$ than all the other BP membranes in 300 Table 1 including those containing cross-linked chitosan (MWNT/chitosan- glycerin and 301 MWNT/chitosan- PEGDE). Contact angle results in Table 1 also indicate that the 302 MWNT/chitosan BP membrane has a hydrophobic surface (i.e. less likely to adsorb or be 303 wetted by water). However, the contact-angle values for the MWNT/chitosan-glycerin 304 and MWNT/chitosan-PEGDE (crosslinked chitosan) BP membranes were $80 \pm 2^{\circ}$ and 76 $305 \pm 3^{\circ}$ respectively, showing hydrophilicity. The high contact-angle value of the 306 MWNT/chitosan BP suggests that most of the membrane's surface consisted of MWNT. 307 It is likely that some of the chitosan was lost during the filtration process. The contact 
angles of the three BP membranes are also consistent with their respective conductivity results (Table 1), MWNT/chitosan exhibited the highest conductivity. This could also indicate that there was a greater proportion of MWNT on its surface than on the other membranes. Moreover, the obtained contact-angle values (Table 1) were significantly

312 higher than those of other studies. For example, the contact angle values of the 313 MWNT/chitosan composite membranes decreased from $86^{\circ}$ to $56.5^{\circ}$ [35]. In addition, 314 Table 1 shows that the contact angle of the MWNT buckypapers fall within the range 76 $315 \pm 3^{\circ}$ to $102 \pm 3^{\circ}$. This is a significantly high values compared to those reported 316 previously (Table 1) for the MWNT dispersed with different dispersants (cipro and Trix) 317 [16]. This is indicated that the contact angle values of BP membranes (MWNT/chitosan 318 and MWNT/chitosan-crosslinked) are affected by using biopolymers such as chitosan and chitosan-crosslinked as dispersants.

\subsection{Morphology of BP membranes}

SEM images of the three BP membranes (MWNT/chitosan, MWNT/chitosan322 glycerin and MWNT/chitosan-PEGDE) are shown in Fig 4. MWNT (0.1\% w/v), chitosan $323(0.2 \% \mathrm{w} / \mathrm{v})$ and glycerin or PEGDE ( $20 \%$ by weight relative to chitosan) were used. In 324 the case of MWNT/chitosan-crosslinked BP membranes (Fig 4C and E), nanopore 325 formation occurs during the crosslinking method. In other words, these BP membranes 326 fabricated with dispersions containing MWNT/chitosan-glycerin or MWNT/chitosan327 PEGDE exhibit pore formation. This pore formation is related to phase separation 328 through the crosslinking method, which generally occurs when chitosan is crosslinked in the presence of glycerin or PEGDE [36, 37]. Thus, pores formation at the surface can be observed in the SEM images of MWNT/chitosan-PEGDE (Fig 4E). Also, lesser pores are observed in the images of MWNT/chitosan-glycerin (Fig 4C). This indicates that the 332 pores on the surfaces of the BP membranes are highly dependent on the identity of the 333 dispersants used. In contrast, the MWNT/chitosan (Fig 4A) revealed a randomly 334 entangled mat/network of MWNTs with small-sized pores between bundles of nanotubes. 335 Moreover, the SEM images of the three BP membranes show that the MWNTs are well 336 dispersed through the chitosan and crosslinked chitosan solutions (i.e. there are no many 337 aggregates). However, it is clear from the SEM images (Fig 4A, C and E) that the BP 
338 membranes had much larger agglomerates of nanotubes with small numbers of 339 irregularly sized pores compared to those of the BP membranes formed from 340 MWNT/Trix [16, 38]. Whitten et al.[39] had similar results for single-walled nanotubes 341 (SWNTs) membranes, showing that biopolymers (chitosan) can suspend much larger 342 agglomerates of nanotubes than low-molecular-weight (Trix) dispersant because of their 343 greater molecular weights. Additionally, the SEM images of cross section (Fig 4B, D and 344 F) show that there is no difference in the structures of the fractures of the three 345 buckypaper membranes, all showing numbers of the MWNTs layers in their structure, 346 except for the few different numbers of MWNTs layers.With providing very narrow 347 spaces between MWNTs and more contents of MWNTs were found from the surface 348 layer. 

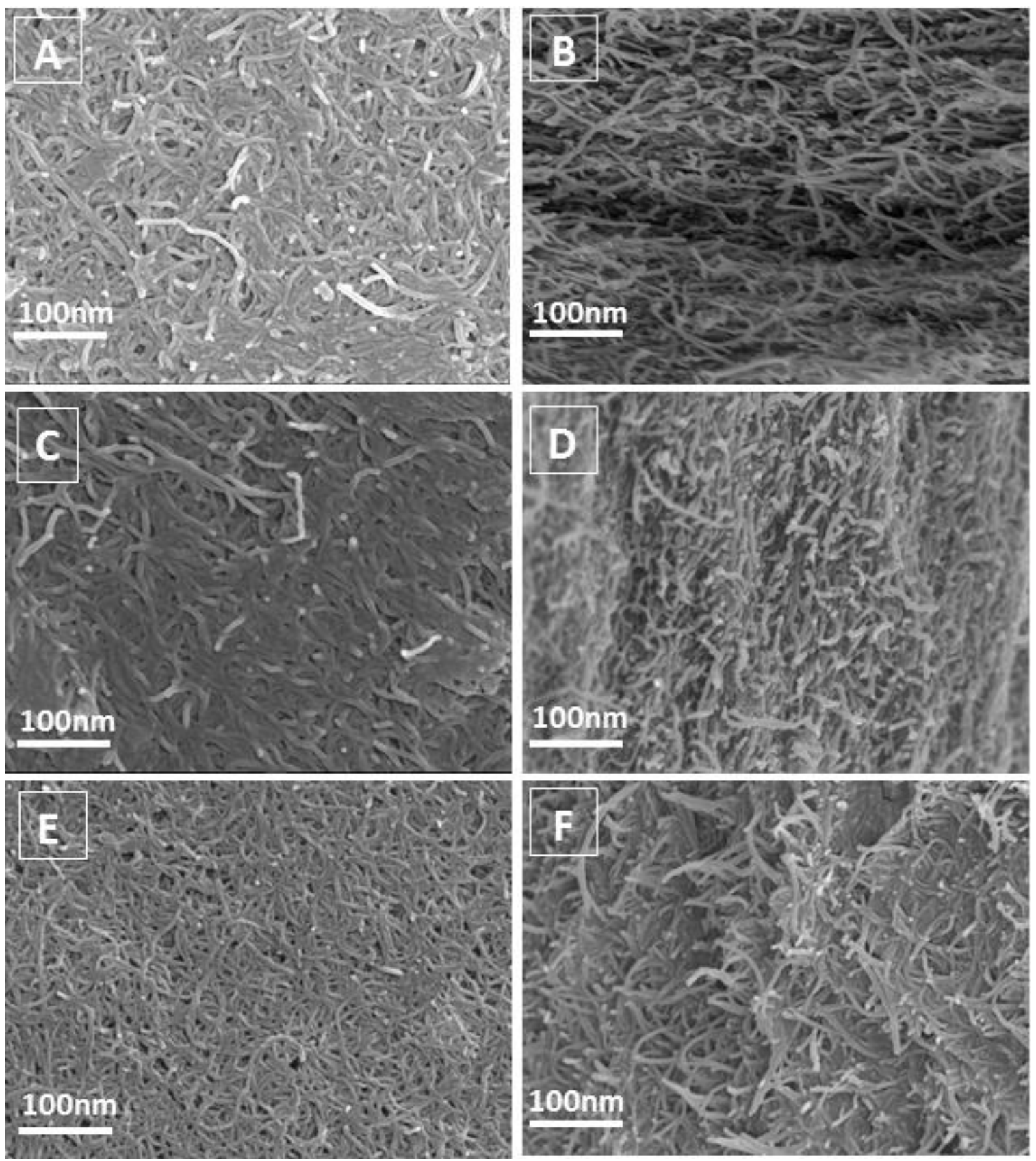

Fig 4. SEM images of the surface and cross-section morphology of the three BP membranes: A and B) MWNT/chitosan BP; C and D) MWNT/chitosan-glycerin BP; and E and F) MWNT/chitosan-PEGDE BP 353 containing $0.1 \%(\mathrm{w} / \mathrm{v})$ MWNTs and different dispersants (chitosan, chitosan-glycerin and chitosan354 PEGDE) for $30 \mathrm{~min}$.

3.5 Mechanical characteristics membranes for filtration. Typically, straightforward strategies were used to detect high- 
359 performance engineering polymers for membrane materials, to improve crosslinked 360 polymers or to produce polymer composite membranes [40, 41]. In this work, tensile 361 stress-strain curves of the MWNT/chitosan and MWNT/chitosan-crosslinked membrane 362 samples were developed as discussed earlier and are shown in Fig 5. The values of the 363 tensile properties (i.e. elongation, tensile strength, Young's modulus and toughness) are 364 summarised above in Table 1. These properties for the three BP membranes fell within a 365 relatively small range of values. For example, the tensile strength of MWNT/chitosan366 PEGDE (59 $\pm 3 \mathrm{MPa})$ was slightly higher than for MWNT/chitosan $(56 \pm 3 \mathrm{MPa})$ and 367 MWNT/chitosan-glycerin (49 $\pm 4 \mathrm{MPa})$. Moreover, MWNT/chitosan-PEGDE BP had the 368 lowest value of Young's modulus, at $2.67 \pm 0.19 \mathrm{GPa}$. The values for MWNT-chitosan 369 were $2.91 \pm 0.11 \mathrm{GPa}$, and $2.82 \pm 0.19 \mathrm{GPa}$ for MWNT/chitosan-glycerin. In contrast, the 370 elongation-to-break value for the MWNT/chitosan BP membranes was $5.7 \pm 0.5 \%$, which 371 is lower than the values obtained for both of the crosslinked membranes (i.e. $8.1 \pm 2 \%$ 372 and $6.4 \pm 2 \%$ for the MWNT/chitosan-PEGDE and the MWNT/chitosan-glycerin 373 membranes respectively). The toughness value of the MWNT/chitosan-PEGDE BP 374 membrane was highest $(3.8 \pm 0.8 \mathrm{~J} / \mathrm{g})$. These enhanced mechanical properties can be 375 attributed to the addition of PEGDE (cross-linking agent), which may be bonded with 376 amino groups of chitosan [24]. Further, all the mechanical properties reported here were 377 much higher than the mechanical properties of BPs prepared by the vacuum-filtration 378 method using MWNTs and various dispersions, such as Trix, cipro and $\tau$-carrageenan as 379 summarized in Table 1 [16, 42]. A previous investigation supports this hypothesis, 380 showing that only when high molecular mass dispersants, such as polysaccharides and 381 proteins, were included in the membrane, was there a significant increase in the strength 382 of SWNT BPs [20]. 


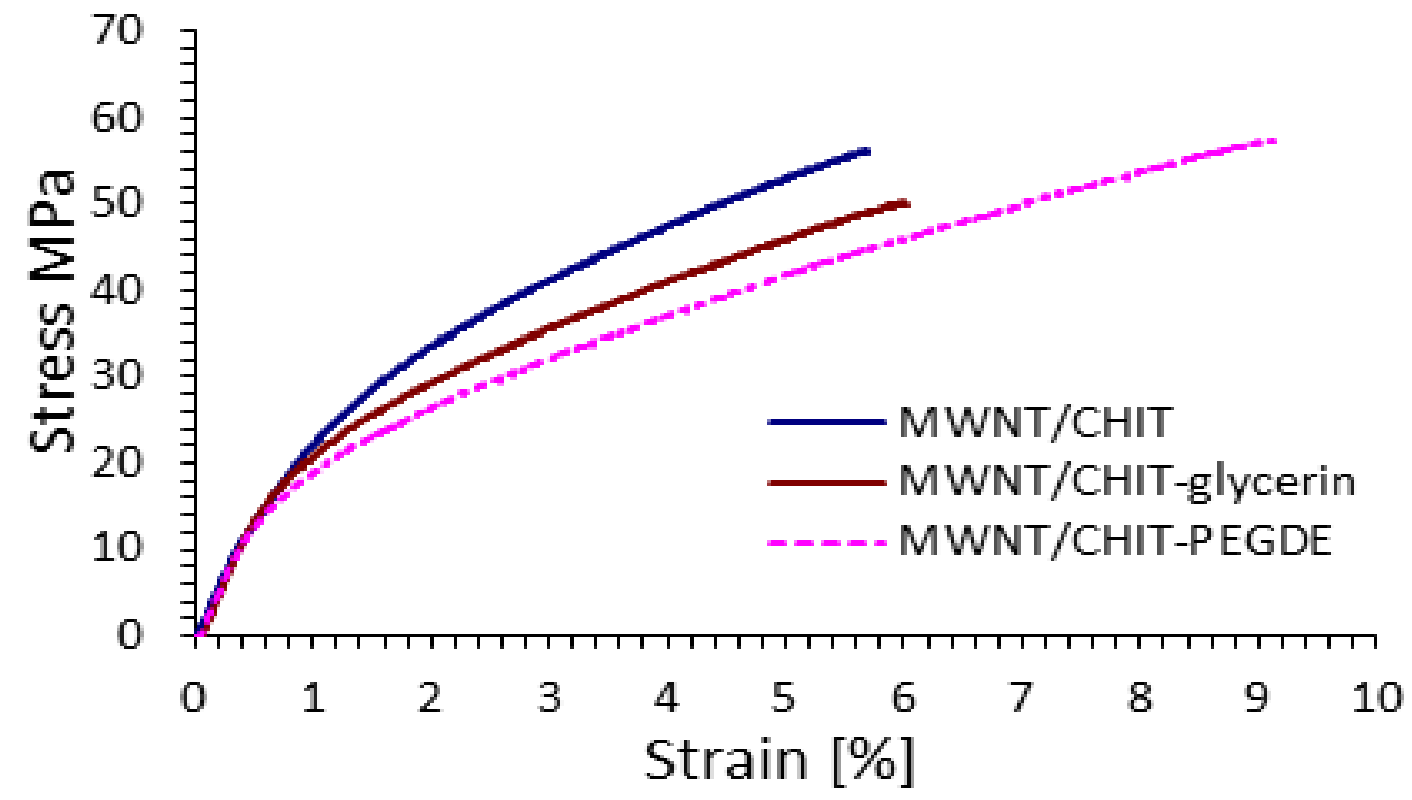

Fig 5. Stress-strain curves of MWNT/chitosan and MWNT/chitosan-crosslinked (MWNT/CHIT-glycerin and MWNT/CHIT-PEGDE) BP membranes.

\subsection{Solubility} group in its structure with the capacity for pronation and formation of a water-soluble substance. Therefore, crosslinking treatment is required to reinforce the chemical stability of chitosan membranes in low-pH or acidic solutions. It is well known that chitosan can be chemically crosslinked with a variety of crosslinking agents [24, 43]. Ngah et al. [43]

393 reported that the crosslinked chitosan was insoluble. In this study, the solubility 394 behaviours of MWNT-chitosan and MWNT-chitosan-crosslinked BP membranes were 395 determined and are summarized in Table 2. The solubility results showed that the MWNT combined with pure chitosan (not cross-linked MWNT/chitosan) was soluble in acidic 397 solution but insoluble in Milli-Q water and $\mathrm{NaOH}$ solution. This is because chitosan has a 398 primary amine group $\left(-\mathrm{NH}_{2}\right)$ that makes it easily soluble in dilute acid solutions [43]. 399 However, after crosslinking, MWNT-chitosan-glycerin and MWNT/chitosan-PEGDE 400 membranes were insoluble in Milli-Q water and acidic and alkaline solutions (Table 2). 401 In addition, the results reported in this work for the solubility of MWNT/chitosan and 402 MWNT/chitosan-PEGDE are consistent with results obtained in a previous study on 403 chitosan and cross-linked chitosan (chitosan-PEGDE) [43]. 
Table 2. Solubility effect of MWNT-chitosan and MWNT-chitosan-crosslinked BP membranes tested on their solubility in 1-5\% (v/v) acetic acid, Milli-Q water and 3-M sodium hydroxide.

\begin{tabular}{|c|c|c|c|c|c|}
\hline \multirow[t]{2}{*}{ BP membrane } & \multicolumn{5}{|c|}{ Solvent } \\
\hline & Milli-Q & Acetic & Acetic & Acetic & $\mathrm{NaOH}$ \\
\hline & water & acid & acid & acid & \\
\hline & & $1 \%(\mathrm{v} / \mathrm{v})$ & $3 \%(\mathrm{v} / \mathrm{v})$ & $5 \%(\mathrm{v} / \mathrm{v})$ & $3 \mathrm{M}$ \\
\hline MWNT/chitosan & insoluble & soluble & soluble & soluble & insoluble \\
\hline MWNT/chitosan-glycerin & insoluble & insoluble & insoluble & insoluble & insoluble \\
\hline MWNT/chitosan-PEGDE & insoluble & insoluble & insoluble & insoluble & insoluble \\
\hline
\end{tabular}

\subsection{Swelling ratio}

The swelling behaviours of the MWNT/chitosan and MWNT/chitosancrosslinked membranes were calculated using equation 1, and the results are listed in Table 3. The results reveal that the MWNT/chitosan BP membrane had a greater degree of swelling than the MWNT/chitosan-glycerin and MWNT/chitosan-PEGDE BP membranes in Milli-Q water $(\sim 7 \mathrm{pH})$ due to the higher numbers of hydroxyl groups attached to uncrossed chitosan. On the other hand, the swelling results at $\mathrm{pH} \sim 7$ are consistent with values previously reported for chitosan hydrogels cross-linked at the surface with other crosslinkers, such as glutaraldehyde [44]. At low pH (acetic-acid solutions), the MWNT-chitosan BP membranes dissolved, making it impossible to estimate the swelling behaviours due to their physical instability [45]. However, bonding glycerin or PEGDE onto the MWNT/chitosan BP membranes improved the swelling resistance in water, acetic acid and sodium hydroxide. Therefore, the MWNT/chitosanglycerin and MWNT/chitosan-PEGDE BP membranes are stable in acidic and basic solutions and do not swell to the same extent as the MWNT/chitosan BP membrane in aqueous solution. The swelling of chitosan is caused by the electrostatic repulsion between chitosan chains [46]. Tanabe et al. [47] reported that the swelling of chitosan composite membranes can be decreased by preventing the movement of chitosan chains, suggesting that the observed decrease in swelling could be attributed to the hydrogen bonding between glycerin and chitosan that limits chitosan chain movement. 
Table 3. Comparison of the swelling behavior and thickness of MWNT-chitosan and MWNT-chitosancrosslinked: the swelling behaviours of the three BP membranes were measured in $1-5 \%(\mathrm{v} / \mathrm{v})$ each of acetic acid, Milli-Q water and 3-M sodium hydroxide by adding three small pieces $(1 \mathrm{~cm} \times 1 \mathrm{~cm}) \mathrm{of} B P$ membrane to each solution for $24 \mathrm{~h}$ at $21^{\circ} \mathrm{C}$.

\begin{tabular}{|c|c|c|c|c|c|c|}
\hline \multirow[b]{2}{*}{ BP membrane } & \multicolumn{5}{|c|}{ Swelling (\%) } & Thickness \\
\hline & $\begin{array}{c}\text { Milli-Q } \\
\text { water }\end{array}$ & $\begin{array}{c}\text { Acetic } \\
\text { acid } \\
1 \%(\mathrm{v} / \mathrm{v})\end{array}$ & $\begin{array}{c}\text { Acetic } \\
\text { acid } \\
3 \%(v / v)\end{array}$ & $\begin{array}{c}\text { Acetic } \\
\text { acid } \\
5 \%(v / v)\end{array}$ & $\begin{array}{c}\mathrm{NaOH} \\
3 \mathrm{M}\end{array}$ & \\
\hline
\end{tabular}

MWNT/chitosan

$331 \pm 15$

$-$

$-$

$196 \pm 11$

$52 \pm 3$

MWNT/chitosan-

glycerin

$34 \pm 5$

$45 \pm 6$

$83 \pm 10$

$88 \pm 8$

$54 \pm 2$

$52 \pm 6$

MWNT/chitosan-

PEGDE

$$
52 \pm 3
$$

$82 \pm 9$

$104 \pm 10$

$105 \pm 10$

$52 \pm 6$

$58 \pm 4$

431

\subsection{Surface areas and pore structures of membranes}

Nitrogen adsorption/desorption isotherms were obtained at $77 \mathrm{~K}$ to further investigate the interbundle and intrabundle pore structures and surfaces of the three BP membranes. Nitrogen adsorption/desorption isotherms also allowed the evaluation of the specific surface areas of the BPs, as well as the average pore diameter. Typical isotherms

437 obtained from these membranes are shown in Fig 6, and various data derived from the 438 isotherms are presented in

Table 4. Results in Table 4 show that the specific surface areas of three BPs membranes (MWNT/chitosan, MWNT/chitosan-glycerin and MWNT/chitosan-PEGDE) were

441 significantly lower than those determined in previous studies of BP membranes prepared 442 using MWNTs and MWNTs with other dispersants ( 


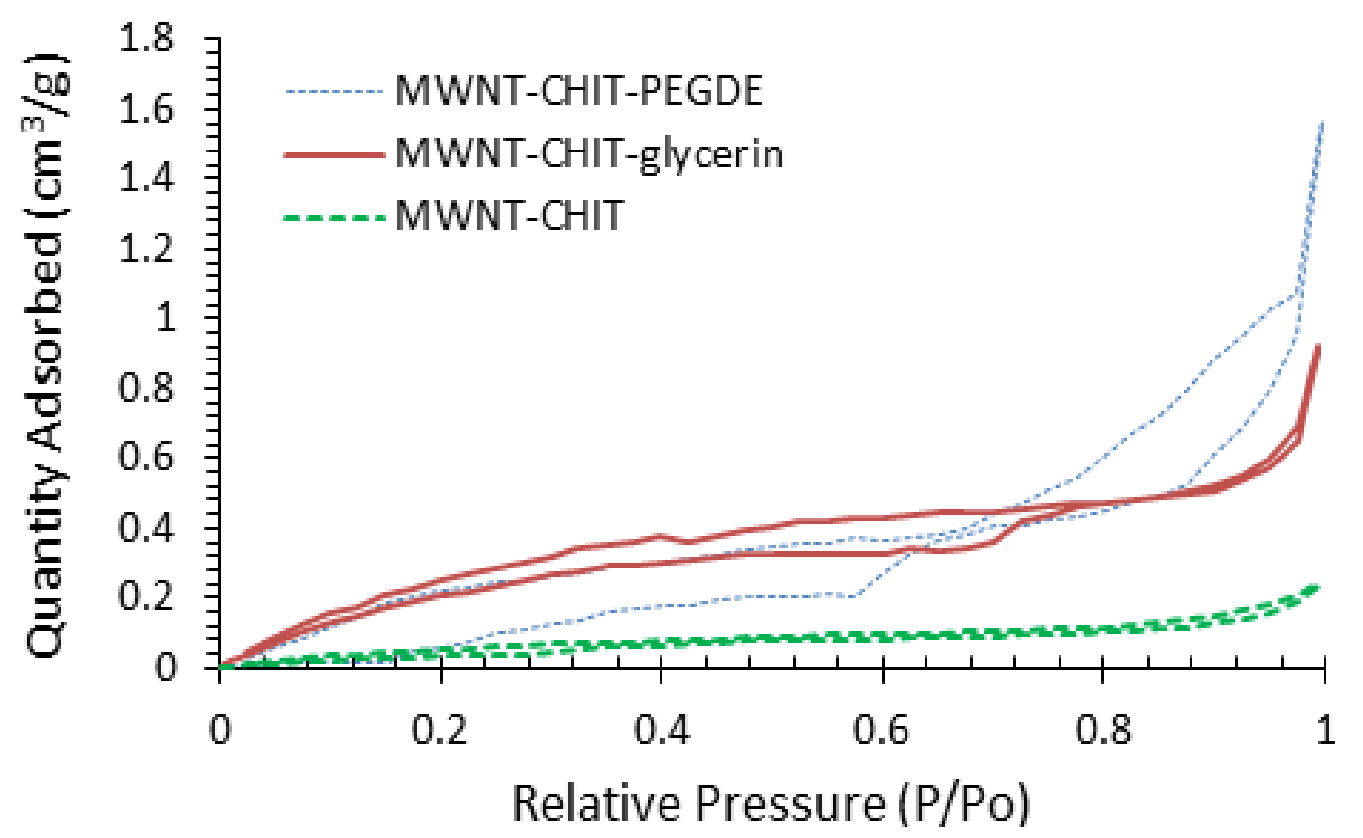

447 Fig 6. Adsorption isotherm demonstrates a comparative plot of the $P / P_{o}$ and adsorption of all BP 448 membranes fabricated using a filtration method.

Table 4. The surface areas $\left(A_{B E T}\right)$, average pore diameters $\left(d_{B E T}\right)$, average interbundle pore volume $\left(D_{b u n}\right)$ and water permeability of MWNT/chitosan, MWNT/chitosan-glycerine and MWNT/chitosan-PEGDE BP membranes.

\begin{tabular}{|c|c|c|c|c|}
\hline Membrane & $\begin{array}{c}\mathrm{A}_{\mathrm{BET}} \\
\text { BP membrane } \\
\left(\mathrm{m}^{2} / \mathrm{g}\right)\end{array}$ & $\begin{array}{c}\text { Pore } \\
\text { diameter } \\
(\mathrm{nm})\end{array}$ & $\begin{array}{c}\text { Interbundle } \\
\text { pore volume } \\
(\%)\end{array}$ & $\begin{array}{c}\text { Water } \\
\text { permeability } \\
\left(\mathrm{L} \mathrm{m}^{-2} \mathrm{~h}^{-1} \text { bar }^{-1}\right)\end{array}$ \\
\hline MWNT/ Trix ${ }^{a}$ & $300 \pm 1.0$ & $24 \pm 1$ & $91 \pm 5$ & $24 \pm 6$ \\
\hline MWNT/C6S ${ }^{\mathrm{c}}$ & $250 \pm 1.0$ & $26 \pm 3$ & $94 \pm 6$ & $17 \pm 4$ \\
\hline $\mathrm{MWNT} / \mathrm{PTS}^{\mathrm{c}}$ & $180 \pm 0.1$ & $20 \pm 2$ & $96 \pm 8$ & $23 \pm 6$ \\
\hline $\mathrm{MWNT} / \mathrm{TSP}^{\mathrm{c}}$ & $240 \pm 1.0$ & $26 \pm 3$ & $92 \pm 5$ & $21 \pm 3$ \\
\hline MWNT/chitosan & $11 \pm 2$ & $3.7 \pm 0.1$ & $67 \pm 4$ & $0.87 \pm 0.03$ \\
\hline MWNT/chitosan-glycerin & $1 \pm 0.2$ & $2.5 \pm 0.1$ & $13 \pm 1$ & $0.61 \pm 0.02$ \\
\hline MWNT/chitosan-PEGDE & $0.07 \pm 0.01$ & $2.1 \pm 0.1$ & $*$ & $0.19 \pm 0.01$ \\
\hline
\end{tabular}


Each isotherm in Fig 6 was used to calculate pore-size distribution using the BJH

458 and HK methods $[31,32]$. The HK method provides information relative to the

459 distribution of small pores (i.e. $<2 \mathrm{~nm}$ ), whereas the BJH method can assess relatively the

460 distribution of the large pores of all BP membranes. Results were obtained for pore-size

461 distribution of each BP membrane (Fig 7) by combining the data from these two

462 methods. The large peak from $0.5-1 \mathrm{~nm}$ is related to the pores between MWNT

463 (intrabundle). However, variation $>1 \mathrm{~nm}$ appeared in the distributions of the large pores.

464 These interbundle pores are shown in the SEM images (Fig 4A-C) [49]. Numerical

465 integration of the curves of Fig 7A-C reveal that these larger interbundle pores are

466 responsible for $67 \%$ of the total free volume of MWNT/chitosan and only $13 \%$ of

467 MWNT/chitosan-glycerin. The interbundle pore volume percentages for the three BP

468 membranes are very small compared to the values of the results for the MWNT-Trix,

469 MWNT-C6S, MWNT-PTS and MWNT-TSP, BP membranes as shown in

470 Table $4[16,38]$. In addition, the MWNT BPs investigated in this work have much

471 narrower internal pores separating aggregates of MWNT with a small average diameter.

472 This accounts for why the interbundle pore volumes determined for the MWNT BP

473 membranes (range 13-67\%) are much lower than what was measured previously for the

474 BP membranes composed of SWNTs (range 76-93\%) [15]. Data of the pore structure

475 information resulted through analysis of nitrogen adsorption/desorption isotherm

476 therefore exposed that there are generally some significant differences for BP membranes

477 fabricated using the different classes of CNTs and dispersants. Therefore, the results in

478 this work indicate that it may be possible to control the porosity of BP membranes by

479 using MWNT with chitosan and chitosan-crosslinked to be useful for desalination area. 

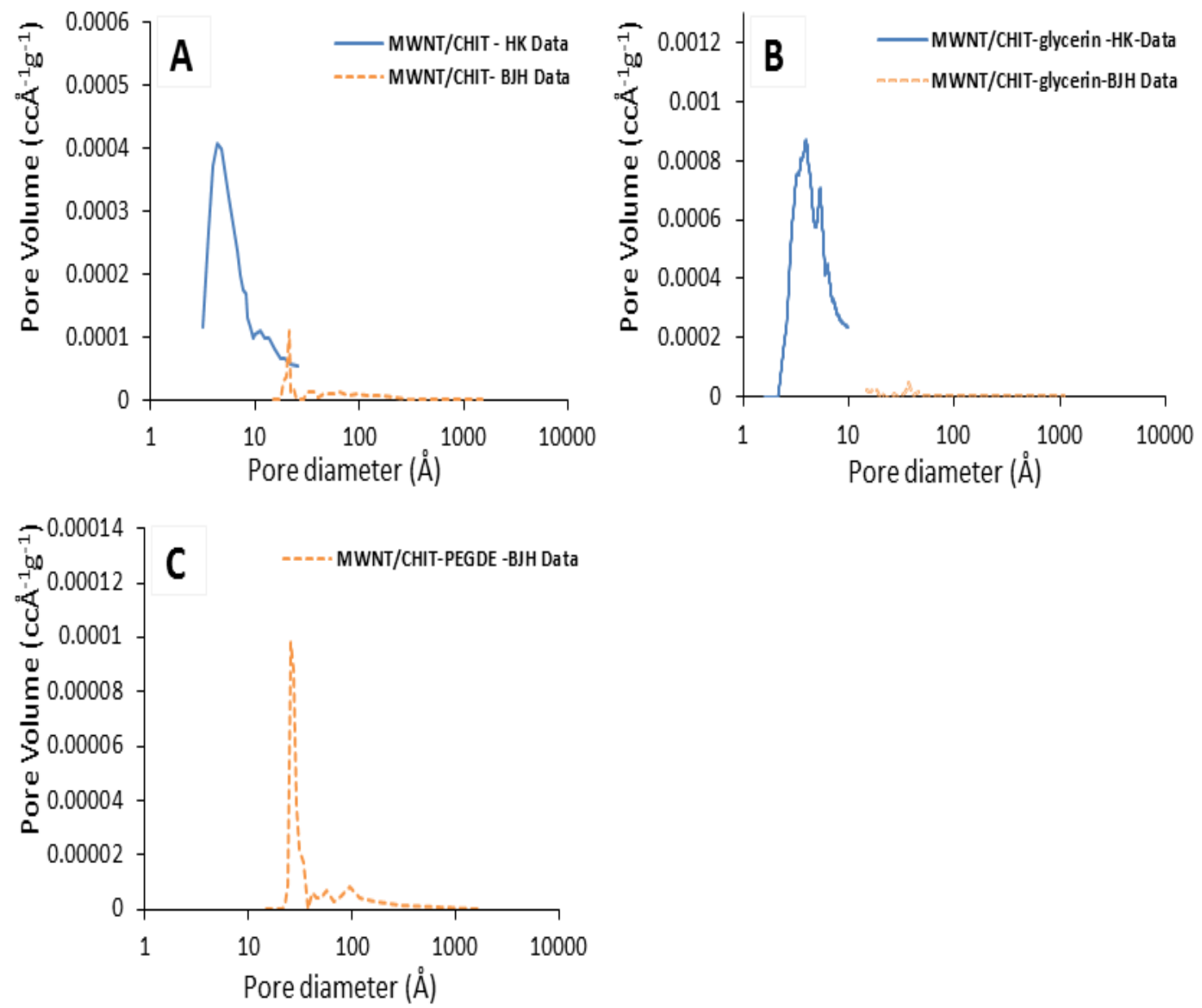

481 Fig 7. Pore-size distributions for BP membranes were determined using the HK (blue peak) and BJH 482 methods (orange dotted peak), which were obtained from nitrogen adsorption/desorption isotherms: A) 483 MWNT/chitosan; B) MWNT/chitosan-glycerin; and C) MWNT/chitosan-PEGDE; all BP membranes were 484 prepared using a filtration method.

\section{$485 \quad 3.9 \quad$ Zeta potential}

486 Membrane-surface charge density can be determined by measuring the membrane 487 surface ZP. Techniques to estimate the ZP have been described in detail by Childress and 488 Elimelech [50]. The ZPs of the three investigated BP membranes were determined by the 489 method described previously in the experimental section. The results are plotted as a 490 function of $\mathrm{pH}$ in Fig 8. All three BP membranes were neutral between $\mathrm{pH} 4$ to 8 . They 491 were slightly positive at below pH 4 and slightly negative at above pH 8. Results in Fig 8 492 are consistent with the fact that MWNTs do not have any ionisable functional groups. 493 The slightly positive and negative charge at below pH 4 and above $\mathrm{pH} 8$ respectively are 494 possibly due to the protonation and deprotonation of the dispersant (i.e. chitosan, 
495 chitosan-glycerin, and chitosan-PEGDE) residuals in the membrane matrix [50, 52]. Our 496 results are also consistent with a previous study Rashid [51], which showed the 497 isoelectric point of the MWNT/Chitosan at near neutral $\mathrm{pH}$ (i.e. 8.6). The membrane 498 prepared by Rashid was slightly positively charged and negatively charged at below and 499 above this isoelectric point of $\mathrm{pH}$ 8.6. Zhan et al [35] prepared CNT-CS BP membranes 500 using a similar approach and reported the isoelectric point of their membranes at $\mathrm{pH}$ 5.3, 501 which is within the range of $\mathrm{pH} 4$ to 8 reported in our study.

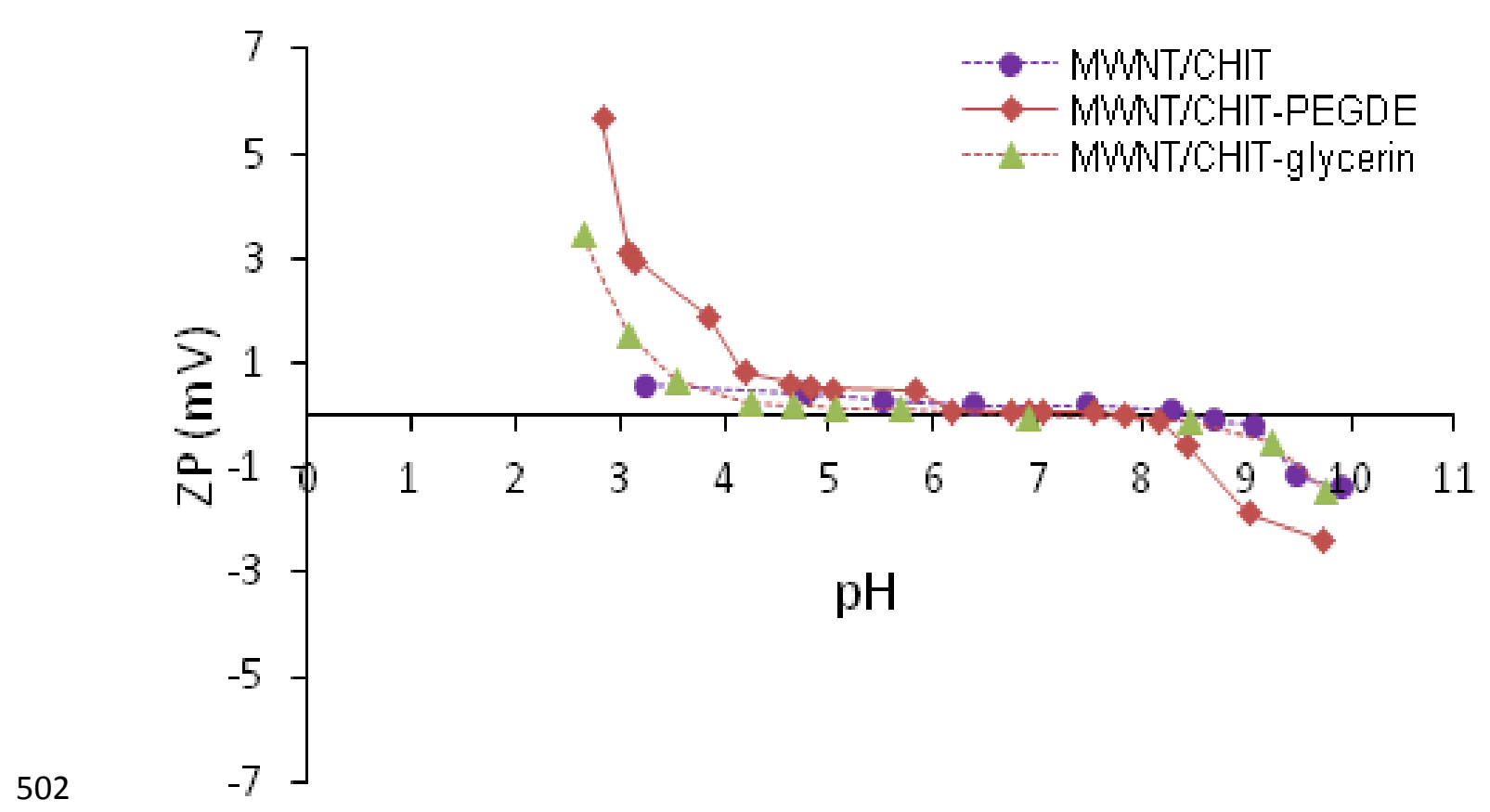

503 Fig 8. ZPs of the three BP membranes as a function of $\mathrm{pH}$.

\subsection{Water permeability}

506 Water permeability was determined for the large BP membranes $\left(40 \mathrm{~cm}^{2}\right)$ using 507 the procedure outlined in the experimental section, wherein the permeate flux was plotted 508 against applied pressure to force the liquid through the membrane. Results are plotted in 509 Fig 9, and water permeability was calculated from the slopes of the liner relationship 510 between permeate flux and applied pressure. 


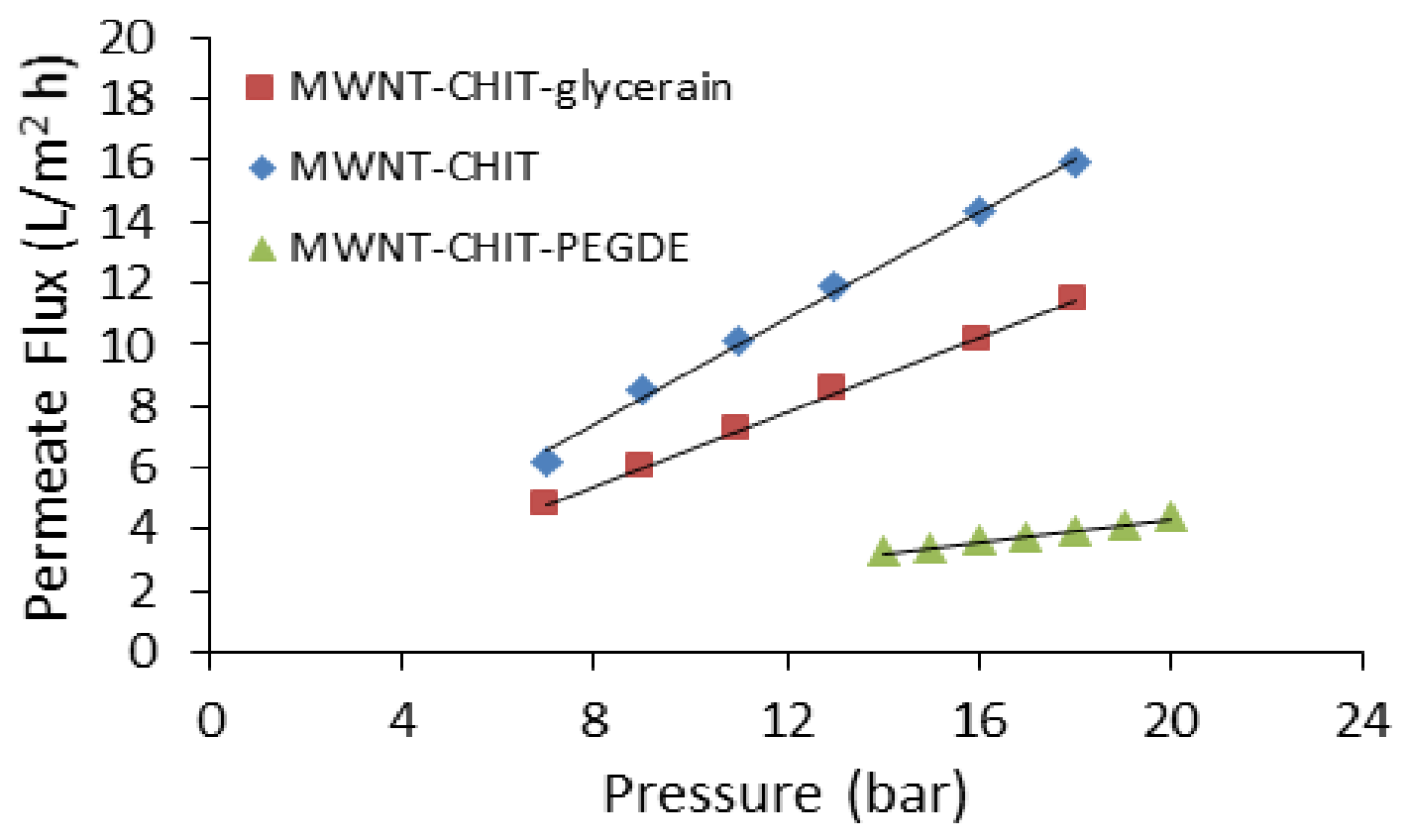

512 Fig 9. Permeate flux as a function of applied pressure of three BP membranes; the resulting straight lines 513 represent a linear fit to the experimental data obtained.

The permeate fluxes of all BP membranes (i.e. MWNT/chitosan and

516 MWNT/chitosan-crosslinked) increased with greater applied pressure [15]; results are

517 presented in

Table 4. After $8 \mathrm{~h}$ of operation for each BP membrane, the MWNT/chitosan BP 519 membrane exhibited an average water-permeability rate of approximately $0.867 \pm 0.03 \mathrm{~L}$

$520 \mathrm{~m}^{-2} \mathrm{~h}^{-1}$ bar. This was 1.3 times higher than the average water-permeability rate $(0.605 \pm$ $5210.02 \mathrm{~L} \mathrm{~m}^{-2} \mathrm{~h}^{-1} \mathrm{bar}^{-1}$ ) of the MWNT/chitosan-glycerin, and 4.4 times greater than the 522 average water-permeability rate $\left(0.189 \pm 0.1 \mathrm{~L} \mathrm{~m}^{-2} \mathrm{~h}^{-1} \mathrm{bar}^{-1}\right)$ of the MWNT/chitosan523 PEGDE. In particular, the water permeability obtained with the MWNT/chitosan-PEGDE 524 BP membrane was significantly lower (approximately a 78\% decrease in flux during an $5258 \mathrm{~h}$ filtration experiment) than that obtained with the MWNT/chitosan membrane. Many 526 studies have reported that the crosslinking (crosslinking agent) of chitosan membranes 527 caused reductions in pore size and water permeability [53-55]. The water permeability 528 results for three BPs in this work are agreed well with those results reported for the 529 surface and pore size as shown in 
Table 4. Therefore, the MWNT/chitosan-crosslinked (MWNT/chitosan-PEGDE)

531 can cause a reduction in membrane permeability when filtering pure water.

\section{$532 \quad 3.11$ Salt-rejection capability}

533 Salt rejection by the three BP membranes (MWNT/chitosan, MWNT/ chitosan534 glycerin and MWNT/chitosan-PEGDE) was determined using a crossflow RO/NF system 535 as shown in Fig. 1 with four inorganic electrolytic solutions $\mathrm{NaCl}, \mathrm{MgCl}_{2}, \mathrm{MgSO}_{4}$ and $536 \mathrm{Na}_{2} \mathrm{SO}_{4}$ (experiments were carried out as a single salt solution) having salt concentrations 537 of $2 \mathrm{~g} / \mathrm{L}$ and applied different pressures at a temperature of $20 \pm 2{ }^{\circ} \mathrm{C}$ for $8 \mathrm{~h}$. Rejection of 538 each salt by the MWNT/chitosan, MWNT/chitosan-glycerin and MWNT/ chitosan539 PEGDE membranes (as described by equation 2 in the experimental section) were plotted 540 against permeate flux (Fig 10).

541 Overall, salt rejection increased as the permeate flux increased. $\mathrm{NaCl}$ rejection by 542 the MWNT/chitosan-PEGDE membrane was the highest (46-63\%) among all three 543 membranes investigated here. This value was approximately, three time higher than the 544 average $\mathrm{NaCl}$ rejection by the MWNT/chitosan membrane (approximately 21\%) and two 545 time higher than the average $\mathrm{NaCl}$ rejection of MWNT/chitosan-Glycerin (approximately 546 19-38\%). These results are consistent to the measured pore size of the investigated BP 547 membranes (Table 4) where the MWNT/chitosan-PEGDE membrane showed the 548 smallest pore size. A similar rejection data for $\mathrm{NaCl}$ using different type of $\mathrm{NF}$ 549 membranes were obtained elsewhere [28]. Moreover, the MWNT/chitosan-PEGDE 550 membrane also had a greater rejection for $\mathrm{MgSO}_{4}$ (approximately 33-37\%) than that of 551 the MWNT/chitosan (18-23\%) and MWNT/chitosan-glycerin membranes (17-23\%). It is 552 noted that $\mathrm{Na}_{2} \mathrm{SO}_{4}$ rejection by these three BP membranes were quite low (Fig 10). $553 \mathrm{Na}_{2} \mathrm{SO}_{4}$ rejection by the MWNT/chitosan was 6-9\%. 

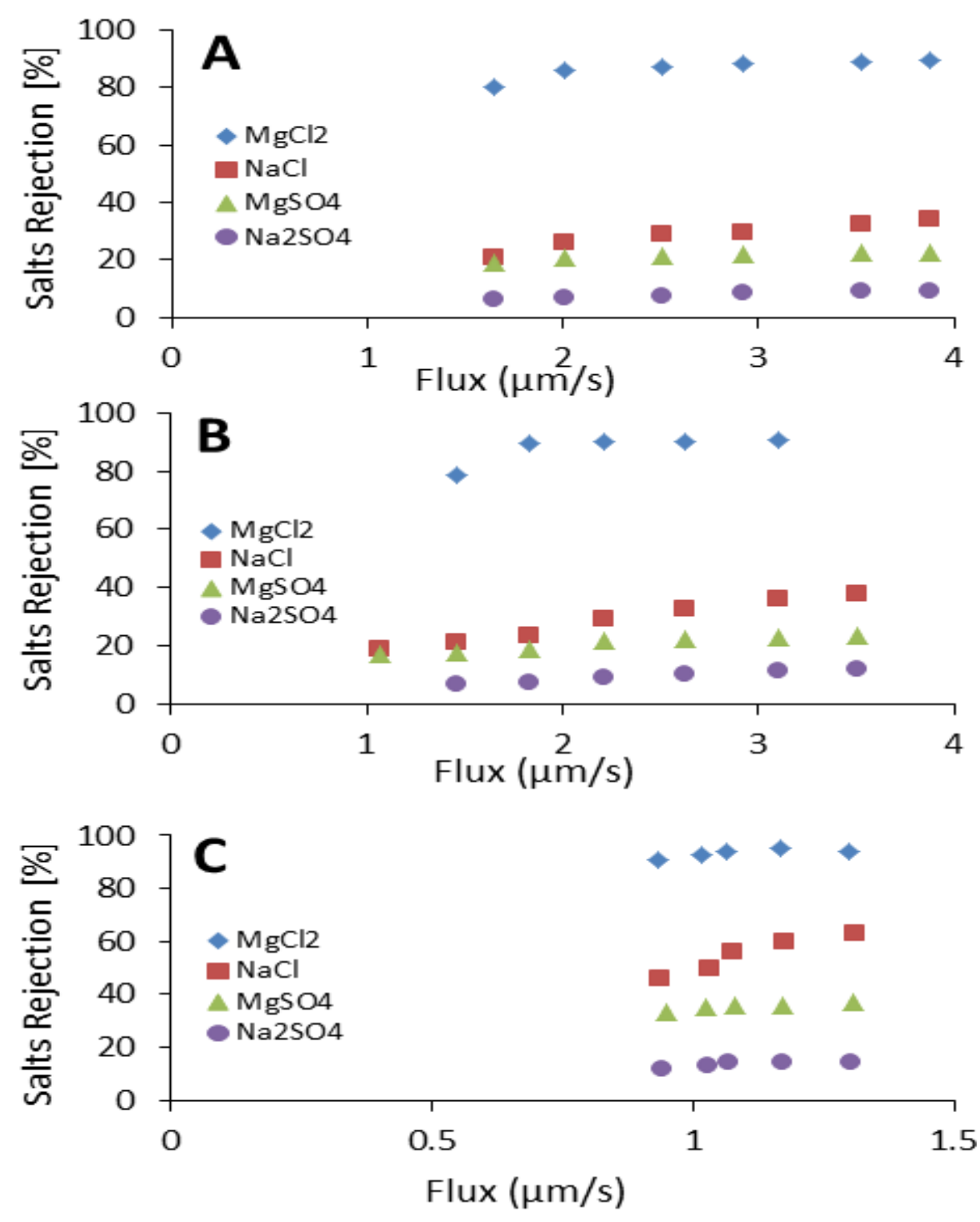

555 Fig 10. Comparison of the observed of salt rejection as a function of permeate flux for the three BP 556 membranes: A) MWNT/chitosan; B) MWNT/chitosan-glycerin; and C) MWNT/chitosan-PEGDE.

558 The observed low rejections of divalent salts (e.g. $\mathrm{MgSO}_{4}$ and $\mathrm{Na}_{2} \mathrm{SO}_{4}$ ) could be 559 explained by the lack of any surface charge of these BP membranes (section 3.9). It is 560 most notable that salt rejection in this research (Fig 10) follows the order of $\mathrm{R}\left(\mathrm{MgCl}_{2}\right)>$ $561 \mathrm{R}(\mathrm{NaCl})>\mathrm{R}\left(\mathrm{MgSO}_{4}\right)>\mathrm{R}\left(\mathrm{Na}_{2} \mathrm{SO}_{4}\right)$ for three $\mathrm{BP}$ membranes under the same operating 562 conditions. These results are in contrast to the rejection behavior of the conventional 563 polyamide NF membranes, in which the rejection of divalent salts is usually higher than 564 that of monovalent salts $[53,56]$. It is noteworthy that the conventional polyamide 565 membranes are significantly negatively charged at around $\mathrm{pH} 7$ and thus electrostatic 

interaction can play a major role in the rejection of cations and anions. By contrast, the 567 MWNT BP membranes in this study were neutral at $\mathrm{pH} 7$, thus, electrostatic interaction is not expected as a major rejection mechanism. Of a particular note, the order of rejection reported here coincides with the decreasing order of unhydrated ionic radius of $\mathrm{Cl}^{-}(0.19$ $\mathrm{nm})>\mathrm{Na}^{+}(0.1 \mathrm{~nm})>\mathrm{Mg}^{2+}(0.09 \mathrm{~nm})$ Kielland [57]. The unhydrated ionic radius of $\mathrm{SO}_{4}{ }^{2-}$ is not available in the literature. The three BP membranes have neutral surface 572 charge at $\mathrm{pH} 7$, which can explain for a higher rejection of mono-valent ions (e.g. $\mathrm{Cl}^{-}$) 573 than for multi-valent ions (e.g. $\mathrm{SO}_{4}{ }^{2-}$ ) for the size effect. Our results are consistent with a previous study by Tongwen et al [58] who also showed that the rejection of various inorganic electrolytes were in the order of $\mathrm{R}\left(\mathrm{MgCl}_{2}\right)>\mathrm{R}(\mathrm{NaCl})>\mathrm{R}\left(\mathrm{MgSO}_{4}\right)$. Similar to our work, the membrane investigated by Tongwen et al., [58] was not negatively charged. The separation of $\mathrm{MgCl}_{2}$ could be higher than that of $\mathrm{Na}_{2} \mathrm{SO}_{4}$ and $\mathrm{NaCl}$, as was also found by Rios et al. [59] in their study of a positively charged membrane. Therefore, the membrane charge determines the dependence of the separation on the electrolyte valence type, on the rejection of salt by the three charged BP membranes, which occur s predominantly through surface interaction between the membrane and ions.

Furthermore, the rejection of $\mathrm{NaCl}$ by MWNT/chitosan and MWNT/chitosancross-linked BP membranes was studied at $20 \pm 2{ }^{\circ} \mathrm{C}$ at the $\mathrm{pH}$ range from 3 to 10 . The transmembrane pressure was adjusted to obtain the same permeate flux for studying the effect of $\mathrm{pH}$ on the salt rejection as presented in Fig 11. All the membranes (MWNT/chitosan and MWNT/chitosan-crosslinked) had increased salt $(\mathrm{NaCl})$ rejection when the feed solution $\mathrm{pH}$ became acidic. The increase in the $\mathrm{NaCl}$ rejection by all three BP membranes when subjected to lower $\mathrm{pH}$ may be attributed to the protonation of free amino groups in chitosan. Previous studies have described that $-\mathrm{NH}_{2}$ on chitosan can be protonated at low $\mathrm{pH}$. As a result, the $\mathrm{NH}_{3}{ }^{+}$group on the chitosan can play an important role because the group is chiefly responsible for interactions with anions and negatively charged surfaces $[60,61]$. Moreover, Fig 11 also demonstrates that the MWNT/chitosanPEGDE membrane had a greater rejection for $\mathrm{NaCl}$ than the $\mathrm{MWNT} /$ chitosan and MWNT/chitosan-glycerin membranes. This may be attributed to the charge repulsion, which can result in higher rejection based on steric interactions. It is likely that the evidence would be much clearer if smaller ions were selected. 


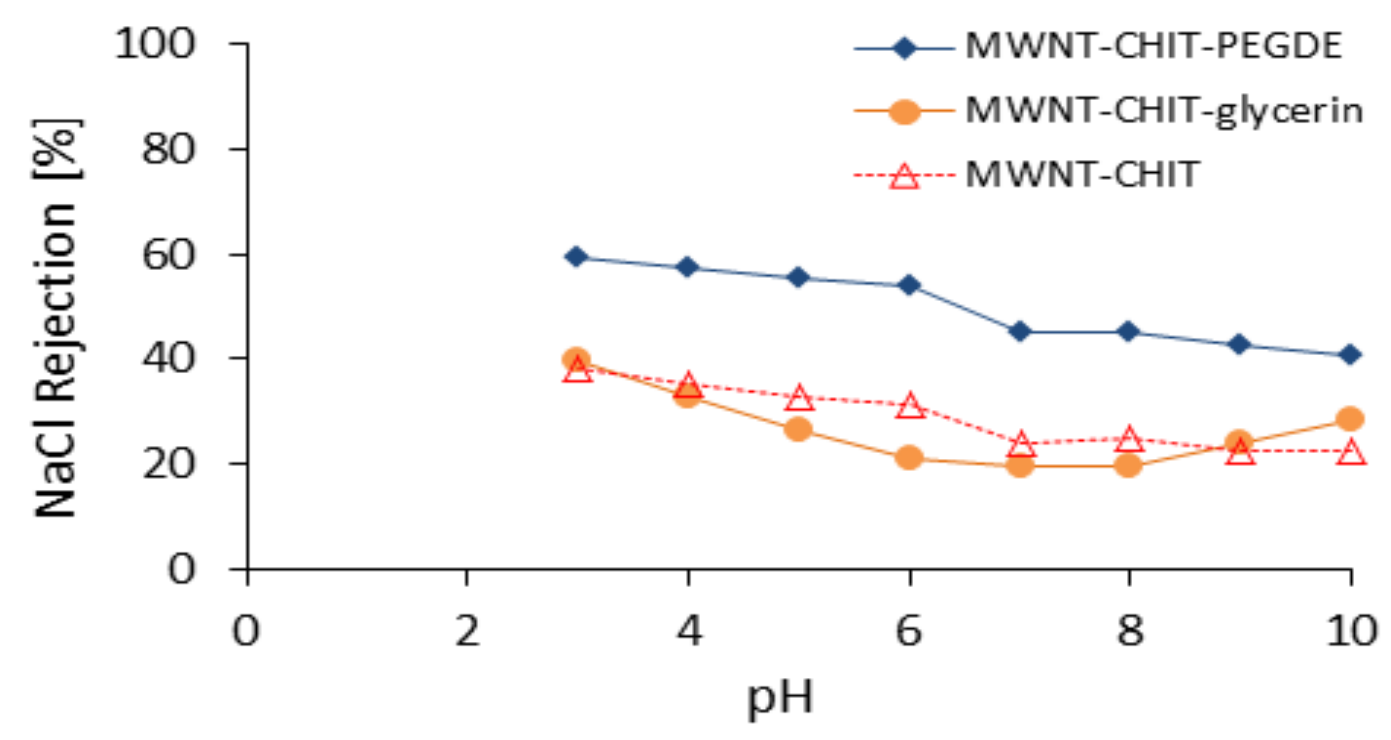

598 Fig 11. Comparison of $\mathrm{NaCl}$ rejection as a function of $\mathrm{pH}$ for the three $\mathrm{BP}$ membranes.

\section{CONCLUSIONS}

Three buckypaper (BP) membranes for nanofiltration application were fabricated 602 from composting multi-walled carbon nanotubes (MWNT) with chitosan containing 603 quaternary amine groups (chitosan and chitosan-crosslinked by in situ amine 604 crosslinking). A comprehensive study for properties of these membranes was 605 investigated. The chitosan, chitosan-glycerin and chitosan-PEGDE as dispersants offered 606 a pathway for enhancing the dispersal of MWNTs in water. In addition, they provided an 607 excellent conductivity range $(60-70 \mathrm{~S} / \mathrm{cm})$, and an extremely high tensile strength 608 compared to the BPs prepared by the vacuum-filtration method using MWNTs and 609 various dispersants, such as Trix, cipro and $\tau$-carrageenan. Contact angle studies for three 610 BP membranes indicated that the crosslinked of chitosan to the glycerin and PEGDE 611 made the surface of membranes more hydrophilic and stable in different solutions. 612 Further, the permeate flux sequence of BP membranes is MWNT/chitosan > 613 MWNT/chitosan-glycerin > MWNT/chitosan-PEGDE. The MWNT/chitosan BP 614 membrane provides more accessible free volume for water transport than the 615 MWNT/chitosan-PEGDE and MWNT/chitosan -glycerin content. Salt rejection of three $616 \mathrm{BP}$ membranes follows the order of $\mathrm{R}\left(\mathrm{MgCl}_{2}\right)>\mathrm{R}(\mathrm{NaCl})>\mathrm{R}\left(\mathrm{MgSO}_{4}\right)>\mathrm{R}\left(\mathrm{Na}_{2} \mathrm{SO}_{4}\right)$ 
under the same operating conditions. These results inidicate that the separation of these inorganic cations and anions are mostly governed by the size of their unhydrated radius.

\section{ACKNOWLEDGMENTS}

620 This work was supported by the University of Wollongong Australia and King Abdul 621 Aziz City for Science and Technology KACST in Saudi Arabia, which provided a 622 scholarship to Ahmed A. Alshahrani to support his $\mathrm{PhD}$. The study was also supported by 623 the Australian Research Council Centre of Excellence and Future Fellowship programs 624 (M. in het Panhuis). The authors acknowledge the use of the facilities and the assistance of Dr T. Romeo at the UOW Electron Microscopy Centre at University of Wollongong 626 Australia. We also thank Sultan Albishi (King Abdul Aziz City for Science and Technology, Saudi Arabia) for his assistance with BET measurements.

\section{REFERENCES}

629 [1] J.N. Coleman, U. Khan, Y.K. Gun'ko, Mechanical reinforcement of polymers using carbon nanotubes, Advanced Materials, 18 (2006) 689-706. [2] M.L. Manchado, L. Valentini, J. Biagiotti, J. Kenny, Thermal and mechanical properties of single-walled carbon nanotubes-polypropylene composites prepared by melt processing, Carbon, 43 (2005) 1499-1505.

634 [3] L. Carson, C. Kelly-Brown, M. Stewart, A. Oki, G. Regisford, J. Stone, P. 635 Traisawatwong, C. Durand-Rougely, Z. Luo, Grafting of chitosan and 636 chitosantrimethoxylsilylpropyl methacrylate on single walled carbon nanotubes-synthesis 637 and characterization, Journal of chemistry and chemical engineering, 4 (2010) 6.

[4] L. Hu, D.S. Hecht, G. Grüner, Carbon nanotube thin films: fabrication, properties, and applications, Chemical reviews, 110 (2010) 5790-5844.

[5] M. Cinke, J. Li, B. Chen, A. Cassell, L. Delzeit, J. Han, M. Meyyappan, Pore structure of raw and purified HiPco single-walled carbon nanotubes, Chemical Physics Letters, 365 (2002) 69-74.

[6] G. Hummer, J.C. Rasaiah, J.P. Noworyta, Water conduction through the hydrophobic channel of a carbon nanotube, Nature, 414 (2001) 188-190.

[7] A. Kalra, S. Garde, G. Hummer, Osmotic water transport through carbon nanotube membranes, Proceedings of the National Academy of Sciences of the United States of America, 100 (2003) 10175-10180.

[8] B.J. Hinds, N. Chopra, T. Rantell, R. Andrews, V. Gavalas, L.G. Bachas, Aligned multiwalled carbon nanotube membranes, Science (New York, N.Y.), 303 (2004) 62-65. A. Noy, O. Bakajin, Fast Mass Transport through Sub-2-Nanometer Carbon Nanotubes, Science, 312 (2006) 1034-1037. 
[10] C. Tang, C. Zhang, Q. Zhang, K. Wang, Q. Fu, Water transport behavior of chitosan 654 porous membranes containing multi-walled carbon nanotubes (MWNTs), Journal of Membrane Science, 337 (2009) 240-247.

658 [12] X. Wang, X. Chen, K. Yoon, D. Fang, B.S. Hsiao, B. Chu, High flux filtration 659 medium based on nanofibrous substrate with hydrophilic nanocomposite coating, 660 Environmental science \& technology, 39 (2005) 7684-7691.

661 [13] Y.T. Ong, S.H. Tan, Synthesis of the novel symmetric buckypaper supported ionic 662 liquid membrane for the dehydration of ethylene glycol by pervaporation, Separation and 663 Purification Technology, 143 (2015) 135-145.

664 [14] M.F. Arif, S. Kumar, T. Shah, Tunable morphology and its influence on electrical, 665 thermal and mechanical properties of carbon nanostructure-buckypaper, Materials \& 666 Design, 101 (2016) 236-244.

667 [15] L.J. Sweetman, L. Nghiem, I. Chironi, G. Triani, M. in het Panhuis, S.F. Ralph, 668 Synthesis, properties and water permeability of SWNT buckypapers, J. Mater. Chem., 22 669 (2012) 138-1381.

670 [16] L .J .Sweetman, L .J .Alcock, J. D. McArthur, E .M. Stewart, G .Triani, M. in het 671 Panhuis, S.F. Ralph, Bacterial Filtration Using Carbon Nanotube/Antibiotic Buckypaper 672 Membranes, Journal of Nanomaterials, 1 (2013) 1-11.

673 [17] J. Gou, Single-walled nanotube bucky paper and nanocomposite, Polymer 674 International, 55 (2006) 1283-1288.

675 [18] C.J. Frizzell, D.H. Coutinho, K.J. Balkus, A.I. Minett, W.J. Blau, J.N. Coleman, 676 Reinforcement of macroscopic carbon nanotube structures by polymer intercalation: The 677 role of polymer molecular weight and chain conformation, Physical Review B, 72 (2005). 678 [19] F.B. Peng, F.S. Pan, H.L. Sun, L.Y. Lu, Z.Y. Jiang, Novel nanocomposite 679 pervaporation membranes composed of poly(vinyl alcohol) and chitosan-wrapped carbon 680 nanotube, Journal of Membrane Science, 300 (2007) 13-19.

681 [20] J. Boge, L.J. Sweetman, M. in het Panhuis, S.F. Ralph, The effect of preparation 682 conditions and biopolymer dispersants on the properties of SWNT buckypapers, J. Mater. 683 Chem, 19, (2009) 9131-9140

684 [21] Y.S. Lee, E.D. Wetzel, N.J. Wagner, The ballistic impact characteristics of Kevlar® 685 woven fabrics impregnated with a colloidal shear thickening fluid, Journal of materials 686 science, 38 (2003) 2825-2833.

687 [22] X. Zeng, E. Ruckenstein, Cross-linked macroporous chitosan anion-exchange 688 membranes for protein separations, Journal of Membrane Science, 148 (1998) 195-205.

689 [23] Y. Koyama, A. Taniguchi, Studies on chitin X. Homogeneous cross-linking of 690 chitosan for enhanced cupric ion adsorption, Journal of Applied Polymer Science, 31 691 (1986) 1951-1954.

692 [24] C. Grgorio, Recent developments in polysaccharide-based materials used as 693 adsorbents in wastewater treatment, Progress in Polymer Science, 30 (2005) 38-70.

694 [25] K. Inoue, Y. Baba, K. Yoshizuka, Adsorption of Metal Ions on Chitosan and 695 Crosslinked Copper (II)-Complexed Chitosan, Bulletin of the Chemical Society of Japan, $69666(1993) 2915-2921$. 
[26] N. Hilal, H. Al-Zoubi, N. Darwish, A.W. Mohammad, Nanofiltration of magnesium chloride, sodium carbonate, and calcium sulphate in salt solutions, Separation science and technology, 40 (2005) 3299-3321.

[27] N. Hilal, H. Al-Zoubi, N.A. Darwish, A.W. Mohammad, Performance of nanofiltration membranes in the treatment of synthetic and real seawater, Separation Science and Technology, 42 (2007) 493-515.

[28] N. Hilal, H. Al-Zoubi, A.W. Mohammad, N. Darwish, Nanofiltration of highly concentrated salt solutions up to seawater salinity, Desalination, 184 (2005) 315-326.

[29] C.J. Ferrisa, M. in het Panhuis, Gel-carbon nanotube composites: the effect of carbon nanotubes on gelation and conductivity behaviour, Soft Matter, 5 (2009) 14661473.

[30] S. Brunauer, P.H. Emmett, E. Teller, Adsorption of Gases in Multimolecular Layers, Journal of the American Chemical Society, 60 (1938) 309-319.

[31] E. P. Barrett, L. G. Joyner, P. P .Halenda, The determination of pore volume and area distribution in porous substancea, Journal of the American Chemical Society, 73 (1951) 373-380.

[32] G.Horvath, K. Kawazoe, Method for the calculation of effective pore size distribution in molecular sieve carbon, Journal of Chemical Engineering of Japan, 16 (1983.) 470-475.

[33] M. Xie, L.D. Nghiem, W.E. Price, M. Elimelech, Comparison of the removal of hydrophobic trace organic contaminants by forward osmosis and reverse osmosis, Water research, 46 (2012) 2683-2692.

[34] L.J. Sweetman, Synthesis, characterisation and applications of carbon nanotube membranes containing macrocycles and antibiotics, in, Dissertation/Thesis, School of Chemistry, Wollongong University, 2012.

[35] Y. Zhan, L. Pan, C. Nie, H. Li, Z. Sun, Carbon nanotube-chitosan composite electrodes for electrochemical removal of $\mathrm{Cu}(\mathrm{II})$ ions, Journal of Alloys and Compounds, 509 (2011) 5667-5671.

[36] B.D. McCloskey, H. Ju, B.D. Freeman, Composite Membranes Based on a Selective Chitosan-Poly(ethylene glycol) Hybrid Layer: Synthesis, Characterization, and Performance in Oil-Water Purification,, Ind. Eng. Chem. Res. , 49 (2010) 366-373.

[37] K. Dusek, Phase separation during the formation of three-dimensional polymers, 16 (1967) 1289-1299.

[38] M.H.O. Rashid, S.Q.T. Pham, L.J. Sweetman, L.J. Alcock, A. Wise, L.D. Nghiem, G. Triani, M.I.H. Panhuis, S.F. Ralph, Synthesis, properties, water and solute permeability of MWNT buckypapers, JOURNAL OF MEMBRANE SCIENCE, 456 (2014) 175-184.

[39] P.G. Whitten, A.A. Gestos, G.M. Spinks, K.J. Gilmore, G.G. Wallace, Free standing carbon nanotube composite bio-electrodes, Journal of Biomedical Materials Research. Part B, Applied Biomaterials, 82 (2007) 37-43.

[40] M. Ulbricht, Advanced functional polymer membranes, Polymer, 47 (2006) 2217 2262.

[41] J.G. Wijmans, R.W. Baker, The solution-diffusion model: a review, Journal of Membrane Science, 107 (1995) 1-21. 
[42] A. Aldalbahi, M. in het Panhuis, Electrical and mechanical characteristics of

buckypapers and evaporative cast films prepared using single and multi-walled carbon nanotubes and the biopolymer carrageenan, Carbon, 50 (2012) 1197-1208.

[43] W.S. Wan Ngah, C.S. Endud, R. Mayanar, Removal of copper(II) ions from aqueous solution onto chitosan and cross-linked chitosan beads, Reactive and Functional Polymers, 50 (2002) 181-190.

[44] F.M. Goycoolea, M.E. Fernández-Valle, I. Aranaz, Á. Heras, PH- and temperaturesensitive chitosan hydrogels: Swelling and MRI studies, Macromolecular Chemistry and Physics, 212 (2011) 887-895.

[45] F. Ganji, M.J. Abdekhodaie, Chitosan-g-PLGA copolymer as a thermosensitive membrane, Carbohydrate Polymers, 80 740-746.

[46] X. Qu, A. Wirsén, A.C. Albertsson, Polymerteknologi, I. Tidigare, Kth, Novel pHsensitive chitosan hydrogels: swelling behavior and states of water, Polymer, 41 (2000) 4589-4598.

[47] T. Tanabe, N. Okitsu, A. Tachibana, K. Yamauchi, Preparation and characterization of keratin-chitosan composite film, Biomaterials, 23 (2002) 817-825.

[48] S. Wang, D. Haldane, R. Liang, J. Smithyman, C. Zhang, B. Wang, Nanoscale infiltration behaviour and through-thickness permeability of carbon nanotube buckypapers, Nanotechnology 24 (2013) 015704.

[49] C.J. Frizzell, M. in het Panhuis, D.H. Coutinho, K.J. Balkus, A.I. Minett, W.J. Blau, J.N. Coleman, Reinforcement of macroscopic carbon nanotube structures by polymer intercalation: The role of polymer molecular weight and chain conformation, Physical Review B 72 (2005) 245420.

[50] A.E. Childress, M. Elimelech, Effect of solution chemistry on the surface charge of polymeric reverse osmosis and nanofiltration membranes, Journal of Membrane Science, 119 (1996) 253-268.

[51] M. Rashid, Synthesis, characterisation and water purification properties of carbon nanotube membranes (buckypapers), in, Dissertation/Thesis,School of Chemistry, Wollongong University, (2016).

[52] A.E. Childress, M. Elimelech, Relating nanofiltration membrane performance to membrane charge (electrokinetic) characteristics, Environmental science \& technology, 34 (2000) 3710-3716.

[53] J. Miao, G.-h. Chen, C.-j. Gao, A novel kind of amphoteric composite nanofiltration membrane prepared from sulfated chitosan (SCS), Desalination, 181 (2005) 173-183.

[54] B. Krajewska, A. Olech, Pore structure of gel chitosan membranes. I. Solute diffusion measurements, Polymer Gels and Networks, 4 (1996) 33-43.

[55] D.A. Musale, A. Kumar, Effects of surface crosslinking on sieving characteristics of chitosan/poly(acrylonitrile) composite nanofiltration membranes, Separation and Purification Technology, 21 (2000) 27-37.

[56] M.D. Afonso, M.N. de Pinho, Transport of $\mathrm{MgSO}<\mathrm{sub}>4</ \mathrm{sub}>, \mathrm{MgCl}<\mathrm{sub}>$ $2</$ sub $>$, and $\mathrm{Na}<\mathrm{sub}>2</ \mathrm{sub}>\mathrm{SO}<\mathrm{sub}>4</$ sub $>$ across an amphoteric nanofiltration membrane, Journal of Membrane Science, 179 (2000) 137-154.

[57] J. Kielland, Individual activity coefficients of ions in aqueous solutions, parameters, 4 (1937) 4.5. 
785 [58] X. Tongwen, Y. Weihua, A novel positively charged composite membranes for 786 nanofiltration prepared from poly (2, 6-dimethyl-1, 4-phenylene oxide) by in situ amines 787 crosslinking, Journal of membrane science, 215 (2003) 25-32.

788 [59] G. Rios, R. Joulie, S. Sarrade, M. Carles, Investigation of ion separation by 789 microporous nanofiltration membranes, AIChE journal, 42 (1996) 2521-2528.

790 [60] O.S. Amuda, A.A. Giwa, I.A. Bello, Removal of heavy metal from industrial 791 wastewater using modified activated coconut shell carbon, Biochemical Engineering 792 Journal, 36 (2007) 174-181.

793 [61] S.M. Nomanbhay, K. Palanisamy, Removal of heavy metal from industrial 794 wastewater using chitosan coated oil palm shell charcoal, Electronic Journal of 795 Biotechnology, 8 (2005) 43-53. 